\title{
Molecular characterization of carbamoyl-phosphate synthetase (CPS1) deficiency using human recombinant CPS1 as a key tool
}

Carmen Diez-Fernandez ${ }^{1,2}$, Ana I Martínez, ${ }^{2}$ Satu Pekkala, ${ }^{2,3}$ Belén Barcelona, ${ }^{1,2,4}$ Isabel PérezArellano, ${ }^{2,4}$ Ana María Guadalajara, ${ }^{2}$ Marshall Summar, ${ }^{5}$ Javier Cervera, ${ }^{1,2,4^{*}}$ Vicente Rubio ${ }^{1,4^{*}}$

${ }^{1}$ Instituto de Biomedicina de Valencia (IBV-CSIC), Spain; ${ }^{2}$ Centro de Investigación Príncipe Felipe, Valencia, Spain; ${ }^{3}$ Current address: Department of Health Sciences, University of Jyväskylä, Finland; ${ }^{4}$ Group 739, CIBERER, ISCIII, Spain; ${ }^{5}$ Childrens National Medical Center, Washington DC, USA

CD-F and AIM have contributed equally to this work

JC and VR have contributed equally to this work

*Correspondencing authors:

Vicente Rubio or Javier Cervera

Instituto de Biomedicina de Valencia

C/ Jaime Roig 11

Valencia-46010, Spain

E-mail: rubio@ibv.csic.es, cervera@ibv.csic.es 


\section{ABSTRACT}

The urea cycle disease carbamoyl-phosphate synthetase deficiency (CPS1D) has been associated with many mutations in the CPS1 gene [Häberle et al. Hum Mutat 2011; 32:579-589]. The disease-causing potential of most of these mutations is unclear. To test the mutations effects, we have developed a system for recombinant expression, mutagenesis, and purification of human carbamoyl-phosphate synthetase 1 (CPS1), a very large, complex and fastidious enzyme. The kinetic and molecular properties of recombinant CPS1 are essentially the same as for natural human CPS1. Glycerol partially replaces the essential activator N-acetyl-L-glutamate (NAG), opening possibilities for treating CPS1D due to NAG site defects. The value of our expression system for elucidating the effects of mutations is demonstrated with eight clinical CPS1 mutations. Five of these mutations decreased enzyme stability, two mutations drastically hampered catalysis, and one vastly impaired NAG activation. In contrast, the polymorphisms p.Thr344Ala and p.Gly1376Ser had no detectable effects. Site-limited proteolysis proved the correctness of the working model for the human CPS1 domain architecture generally used for rationalizing the mutations effects. NAG and its analogue and orphan drug N-carbamoyl-Lglutamate, protected human CPS1 against proteolytic and thermal inactivation in the presence of MgATP, raising hopes of treating CPS1D by chemical chaperoning with N-carbamoyl-Lglutamate.

Keywords: urea cycle, CPS1 deficiency, hyperammonemia, carbamylglutamate 


\section{INTRODUCTION}

Carbamoyl-phosphate synthetase 1 (CPS1) deficiency (CPS1D; MIM\# 237300) is a rare autosomal recessive inborn error of the urea cycle [Häberle et al., 2011], the cycle that detoxifies the neurotoxin ammonia produced in body protein catabolism. Unless promptly treated, the hyperammonemia caused by CPS1D can lead to encephalopathy, coma and death or mental retardation [Brusilow and Horwich, 2001; Häberle et al., 2012]. The time of onset and severity of the presentation appear related to the amount of residual activity of the enzyme in the liver [Shih, 1976].

Human CPS1 (hCPS1), a 1462-amino acid, 160-kDa multidomain mitochondrial liver and intestinal enzymatic protein, catalyzes the complex 3-step reaction that is the first of the urea cycle [Pierson and Brien, 1980; Rubio, 1993; Rubio et al., 1981, Pekkala et al., 2010]:

$$
\begin{aligned}
& 2 \mathrm{NAT}+\mathrm{NH}_{3}+\mathrm{HCO}_{3}^{-} \rightarrow 2 \mathrm{ADP}+\mathrm{P}_{\mathrm{i}}+\mathrm{CP} \\
& (\mathrm{NAG}=\mathrm{N} \text {-acetyl-L-glutamate; essential activator of CPS1; CP = carbamoyl-phosphate) }
\end{aligned}
$$

The CPS1 gene (MIM\# 608307) spans 120 kb, it maps to 2q35 [Summar et al., 1995], comprising 38 exons and 37 introns [Summar et al., 2003]. More than 230 genetic lesions have been reported in CPS1D, with little recurrence, since most mutations are "private" to individual families [Häberle et al., 2011], with about 140 of these mutations being missense changes for which the disease-causing role has not been proven in most cases.

In an earlier study [Yefimenko et al., 2005] we attempted to infer the disease-causing potential of missense mutations found in patients with CPS1D by introducing them in recombinantly expressed Escherichia coli CPS, studying experimentally the consequences of such introduction on the activity or the stability of the purified enzyme. Although useful, this approach had obvious drawbacks due to the limited ( 40\%) sequence identity [Nyunoya et al., 
1985] and the large functional differences between the bacterial and human CPSs. These differences include the use and the lack of use by bacterial CPS of, respectively, glutamine and NAG [Meister, 1989], while CPS1 cannot use glutamine as ammonia donor, utilizing ammonia with high affinity, and it needs NAG as an essential allosteric activator without which it is inactive [Rubio et al., 1981, 1983a]. In fact, the role of the CPS1 N-terminal 40-kDa region (Fig. 1A), corresponding to the glutamine-splitting, small subunit of bacterial CPS [Meister, 1989; Nyunoya et al., 1985] is uncertain in CPS1, and thus, the impact of hCPS1 mutations affecting this region cannot be inferred from E. coli CPS studies. Furthermore, the unique characteristics among CPSs of the NAG activation of CPS1 makes difficult to infer from bacterial CPS studies the impact of hCPS1 mutations mapping in the C-terminal $20-\mathrm{kDa}$ of this enzyme, since this region (the allosteric or regulatory domain, Fig. 1A) hosts the site for NAG [Pekkala et al., 2009, Rodríguez-Aparicio et al., 1989] and must generate the allosteric signal that shift CPS1 from inactive to active.

We now exploit our recent success in producing recombinant rodent CPS1 in a baculovirus/insect cell system [Pekkala et al., 2009], to develop a similar system for recombinant production of pure human CPS1 (rhCPS1). Although harboring an N-terminal His-tag to help purification, rhCPS1 is proven here to have the same properties and characteristics as CPS1 purified from human liver [Pierson and Brien, 1980; Rubio et al. 1981] and the same domain composition as the well-studied rodent enzyme [Evans and Balon, 1988; Marshall and Fahien, 1988; Powers-Lee and Corina, 1986]. We demonstrate the value of this expression system for testing the functional impact of missense mutations found in CPS1D, thus helping infer the disease-causing role of these mutations. Furthermore, we show that NAG and its analogue and orphan drug N-carbamyl-L-glutamate (NCG) importantly decrease hCPS1 susceptibility to 
proteolytic attack and thermal inactivation, raising hopes that NCG might be used as a chemical chaperone for treating CPS1D due to misfolding-causing mutations. The present results have also produced novel information on the significance of the N-terminal and C-terminal domains of CPS1.

\section{PATIENTS AND METHODS}

\section{Patients and CPS1 mutations}

The eight missense mutations chosen (Table 1) were reported [Eeds et al., 2006; Finckh et al., 1998; Kurokawa et al., 2007; Summar, 1998] in seven CPS1D patients with neonatal presentations, implying high disease severity. Patients 4 and 1 (Table 1) were, respectively, homozygous or compound heterozygous for one or two missense mutations, whereas in patients 2 and 6 the mutation was detected in mRNA studies that failed to detect a second mutant allele. The other three patients (Table 1) carried in one allele a missense mutation and in the other a truncation-causing change (nonsense changes in patients 3 and 7; a frameshift in patient 5) that, because of the large protein region deleted, should cause enzyme inactivation. The PolyPhen-2 (http://genetics.bwh.harvard.edu/pph2) [Adzhubei et al., 2010] and MutPred (http://mutpred.mutdb.org) [Li et al., 2009] servers assigned these mutations with a high probability of being pathogenic, whereas they made predictions of benignity for two polymorphisms causing non-synonymous amino acid substitutions [Finckh et al., 1998; Summar et al., 2003] that are studied also here as negative controls (Table 1).

All the mutations dealt with here were already included in the locus-specific database for CPS1 (http://www.lovd.nl/CPS1). Amino acid conservation (Table 1) was determined by 
ClustalW sequence alignment of either CPS1, CPSIII or other CPSs from 15, 6 and 270 species, respectively.

\section{Recombinant human CPS1 production}

Human CPS1 cDNA [Haraguchi et al., 1991] (GenBank entry NM_001875.4), was generated from human liver mRNA [Summar et al., 2003] as two complementary fragments by two RT-PCR reactions with appropriate primers. After sequential incorporation of these fragments into pcDNA3.1 (from Invitrogen), the complete CPS1 cDNA was reconstructed within this plasmid by exploiting a unique HindIII CPS1 site, yielding pcDNA3.1-hCPS1. Then (Supp. Fig. S1) a 3985 bp fragment comprising the CPS1 open reading frame (ORF) from base 580 onwards (base 1 is the A of the translation initiation codon) was excised from this plasmid by BamHI and EcoRI, and was ligated into pFastBac. The ORF encoding mature CPS1 (lacking the N-terminal mitochondrial targeting sequence, bp 1-117) was completed by in-frame ligation of a PCR-generated fragment comprising bp 118-579 of the CPS1 cDNA (primers: Cloning_F and Cloning_R, Supp. Table S1; they incorporate a BamHI site for cloning). This yielded pFastBacCPS1, which encodes mature hCPS1 (amino acids 40-1500) preceded N-terminally by the His 6 tag MSYYHHHHHHDYDIPTTENLYFQGAMDP. Site-directed mutagenesis of pFastBac-CPS1 was performed by the overlapping extension method (Quickchange kit from Stratagene) using the forward and reverse primers given in Supp. Table S1. The correctness of the constructs, the presence of the desired mutation, and the absence of unwanted mutations, were corroborated by sequencing.

For producing rhCPS1 (Supp. Fig. S1), we used the commercial Bac-to-Bac ${ }^{\circledR}$ Baculovirus Expression System (Invitrogen), following the manufacturer's directions. In short, E. coli Max 
Efficiency DH10Bac cells (Invitrogen), transformed with pFastBac-CPS1, were grown on LBagar containing 50/7/10/40/100 $\mu \mathrm{g} / \mathrm{ml}$ of, respectively, kanamycin/ gentamycin/tetracyclin/IPTG/Bluo-Gal. Individual white colonies were inoculated into 5-ml LB medium with the same antibiotics, cultured overnight, and the bacmid was isolated. The baculovirus was produced by transfecting Sf9 insect cells with CPS1 cDNA-carrying (proven by PCR) bacmid, using Cellfectin/Grace medium ( 5 hours, $\left.27^{\circ} \mathrm{C}\right)$, followed by 3 -day culture $\left(27^{\circ} \mathrm{C}\right.$, six-well plate) in Sf900 medium (Invitrogen) containing 0.1\% Pluronic F-68, $50 \mathrm{U} / \mathrm{ml}$ penicillin and $50 \mu \mathrm{g} / \mathrm{ml}$ streptomycin. The culture was centrifuged, and the supernatant was used for baculovirus enrichment by infecting with it (1:60 dilution) a suspension of $1.5 \times 10^{6} \mathrm{Sf9}$ cells $/ \mathrm{ml}$. After 48 -hour culturing $\left(27^{\circ} \mathrm{C}\right.$, orbital shaking at $\left.125 \mathrm{rpm}\right)$ and centrifugation, the supernatant was used to inoculate (1:50 dilution) a fresh cell suspension for CPS1 production, collecting the cells by centrifugation after 3 days of culture as above.

\section{Enzyme purification}

Unless indicated, all steps (Supp. Fig. S1) were at $4^{\circ} \mathrm{C}$. To purify rhCPS1 (wild-type or mutant forms), the insect cell pellet from a $50-\mathrm{ml}$ culture was suspended in $3 \mathrm{ml}$ of a lysis solution [50 mM glycyl-glycine, pH 7.4, $1 \mathrm{mM}$ dithiothreitol (DTT), 10\% glycerol, $20 \mathrm{mM} \mathrm{KCl,}$ $0.1 \%$ Triton $\mathrm{X}-100,5 \mu \mathrm{M}$ E-64 protease inhibitor and $1 \%$ of the protease inhibitor cocktail for His-tagged proteins (Sigma product P8849)] and was thawed (melting ice) and frozen (liquid nitrogen or dry $\mathrm{CO}_{2}$-acetone mixture) three times. After 10-min centrifugation $(16,000 \mathrm{xg})$ and supernatant filtration through a $0.22 \mu \mathrm{m}$ membrane, the supernatant was applied to a HisTrap HP 1-ml column fitted in an ÄKTA FPLC system (GE Healthcare) that was equilibrated with 50 $\mathrm{mM}$ glycyl-glycine $\mathrm{pH}$ 7.4, $1 \mathrm{mM}$ DTT, $10 \%$ glycerol, $0.5 \mathrm{M} \mathrm{NaCl}$, and $20 \mathrm{mM}$ imidazole. 
After a 10-ml column wash, a $15-\mathrm{ml}$ linear gradient of $20-500 \mathrm{mM}$ imidazole in the same solution was applied. The CPS1-containing fractions (monitored by SDS-PAGE) were pooled, concentrated to $3-5 \mathrm{mg}$ protein/ml by centrifugal ultrafiltration $(100-\mathrm{kDa}$ cutoff membrane, Amicon Ultra, Millipore), enriched with 10\% extra glycerol and $1 \mathrm{mM}$ extra DTT, and frozen at $-80^{\circ} \mathrm{C}$

Rat liver CPS1, and E. coli-expressed recombinant Enterococcus faecalis ornithine transcarbamylase (OTC) [Barcelona-Andrés et al., 2002] were purified as reported [Alonso and Rubio, 1983; Marshall and Cohen, 1972].

\section{Enzyme activity assays}

In the standard CPS1 assay, CP was converted to citrulline, which was measured colorimetrically [Pekkala et al., 2009]. The enzyme was incubated $10 \mathrm{~min}$ at $37^{\circ} \mathrm{C}$ in an assay mixture containing $50 \mathrm{mM}$ glycyl-glycine $\mathrm{pH}$ 7.4, $70 \mathrm{mM} \mathrm{KCl}, 1 \mathrm{mM}$ DTT, $20 \mathrm{mM} \mathrm{MgSO}_{4}, 5$ $\mathrm{mM}$ ATP, $35 \mathrm{mM} \mathrm{NH}_{4} \mathrm{Cl}, 50 \mathrm{mM} \mathrm{KHCO}_{3}, 10 \mathrm{mM} \mathrm{NAG}, 5 \mathrm{mM}$ L-ornithine and $4 \mathrm{U} / \mathrm{ml}$ OTC. When the concentration of a substrate was varied, other substrates were kept at the concentrations given above (unless indicated), with $\mathrm{MgSO}_{4}$ being in $15 \mathrm{mM}$ excess over ATP.

Since NCG yields color in the citrulline assay, when testing the NCG concentrationdependence of CPS1 activity, we used a continuous pyruvate kinase/lactate dehydrogenase coupled assay in which ADP production was monitored as NADH oxidation at $340 \mathrm{~nm}$ [Guthorlein and Knappe, 1968]. The assay $\left(37^{\circ} \mathrm{C}\right)$ used the same solution as the standard assay except for the lack of OTC and ornithine and the inclusion of $2.5 \mathrm{mM}$ phosphoenolpyruvate, 0.25 $\mathrm{mM} \mathrm{NADH}, 40 \mu \mathrm{g} / \mathrm{ml}$ pyruvate kinase and $25 \mu \mathrm{g} / \mathrm{ml}$ lactate dehydrogenase. The kinetic parameters for NAG were identical, within experimental error, in this assay and in the standard 
assay. This $\mathrm{NADH}$ oxidation-coupled assay, without $\mathrm{NH}_{4} \mathrm{Cl}$, was used for measuring the $\mathrm{HCO}_{3}^{-}-$ dependent ATPase partial reaction of CPS1. For measurement of the partial reaction of ATP synthesis from CP and ADP, an NADP reduction-coupled assay [Yefimenko et al., 2005] was used, monitoring the absorbance at $340 \mathrm{~nm}$ in a mixture at $37^{\circ} \mathrm{C}$ containing $50 \mathrm{mM}$ glycylglycine pH 7.4, $0.1 \mathrm{M} \mathrm{KCl}, 15 \mathrm{mM} \mathrm{MgSO}_{4}, 15 \mathrm{mM}$ glucose, $0.5 \mathrm{mM}$ ADP, $5 \mathrm{mM} \mathrm{CP}, 10 \mathrm{mM}$ NAG, 1 $\mathrm{mM}$ NADP, $1 \mathrm{mM}$ DTT, $0.1 \mathrm{mg} / \mathrm{ml}$ hexokinase and $25 \mu \mathrm{g} / \mathrm{ml}$ glucose-6-phosphate dehydrogenase.

One CPS1 unit produces per minute $1 \mu \mathrm{mol}$ citrulline or $2 \mu \mathrm{mol}$ ADP. The program GraphPad Prism (GraphPad Software, San Diego, California) was used for curve fitting.

\section{Other techniques}

SDS-PAGE [Laemmli, 1970] was performed in 8\% polyacrylamide gels, with Coomassie staining or, for cell extracts, by western blotting/immunostaining (ECL system, GE Healthcare), utilizing an anti-rat liver CPS1 first antibody [Alonso et al., 1989]. Western blots of rat liver CPS1 protease digests (Fig. 1) were stained with immunoperoxidase [Alonso et al., 1989] using as first antibodies rabbit antisera against the electrophoretically separated [Amero et al., 1994] $\mathrm{N}$-terminal $40-\mathrm{kDa}$ or C-terminal $120-\mathrm{kDa}$ moieties of rat liver CPS1 (produced by limited elastase digestion [Marshall and Fahien, 1988]). Protein was determined according to [Bradford, 1976] using bovine serum albumin as standard.

\section{RESULTS AND DISCUSSION}

\section{Producing human CPS1 in a baculovirus/insect cell system}


In the liver, CPS1 is produced as a precursor that is matured by cleavage of its N-terminal 38-39 amino acids upon entry to the mitochondria [Ryall et al., 1985]. We cloned for recombinant expression the cDNA for human liver CPS1 without the N-terminal 39 codons, which were replaced by a 28 -codon N-terminal His 6 -tag. This allowed testing the effects of the mutations on the mature form of the enzyme (the functional one in vivo). The tag simplified and speeded CPS1 purification, what is important, given the instability of mammalian CPS1 [Raijman and Jones, 1976] and its sensitivity to proteolytic attack [Guadalajara et al., 1983]. The CPS1 expressed here carries the more frequent Thr form of the $\mathrm{p}$.Thr1406Asn polymorphism (rs1047891, Ensemble database; allelic frequencies of $\mathrm{T} / \mathrm{N}$ forms, $\sim 0.7 / 0.3$ ) that has been associated with increased frequency of some vascular pathologies possibly related to decreased citrulline levels and nitric oxide production (see for example [Pearson et al., 2001]).

The procedure used (Supp. Fig. S1), optimized for highest rhCPS1 production, had as important elements the use of insect cells cultured for two weeks after unfreezing, and the infection of the cells with a nominal virus-to-cell ratio of 2 in the final CPS1-production step, leaving 72 hours the infected cells in culture $\left(27^{\circ} \mathrm{C}\right.$, orbital shaking, $\left.125 \mathrm{rev} / \mathrm{min}\right)$, in either 50 or $200 \mathrm{ml}$ of medium, before cell harvesting. Purification was possible weeks after harvesting by freezing cells pellets at $-80^{\circ} \mathrm{C}$.

Prior studies with liver-purified hCPS1 [Pierson and Brien, 1980; Rubio et al., 1981] and even more extensive studies with rat liver CPS1 [Alonso et al., 1992; Guadalajara et al., 1983; Guthöhrlein and Knappe, 1968; Marshall and Fahien, 1985, 1988; Raijman and Jones, 1976] showed that mammalian CPS1 is highly instable, requiring precautions to avoid oxidation, proteolytic cleavage and inactivation of unknown cause but preventable by glycerol. Taking into account these factors, we used for cell extract preparation and in subsequent steps a neutral 
medium at $4^{\circ} \mathrm{C}$ containing $10 \%$ glycerol, $1 \mathrm{mM}$ DTT and a very extensive protease inhibitor cocktail, using a fast 3-step purification protocol consisting of cell disruption by freeze-thawing in $0.1 \%$ Triton X-100-containing CPS1-protecting solution, centrifugal clarification and 0.22 $\mu \mathrm{m}$-pore membrane filtration, and a final step of fast Ni-affinity column chromatography with imidazole gradient elution.

rhCPS1, which represented $\sim 10 \%$ of the soluble cell protein (Supp. Fig. S1, left track of the gel), was largely soluble (not illustrated) and yielded after the column chromatography step $\sim 15 \mathrm{mg}$ per $\mathrm{L}$ of cell culture, of highly active (Table 2), homogeneous and pure enzyme as shown by the finding in SDS-PAGE of a single band migrating as expected for its sequencededuced mass (163.9 kDa). (Supp. Fig. S1, right track of the gel).

\section{Recombinant human CPS1 represents well the natural liver enzyme}

It was important to ascertain that rhCPS1 closely represents in all its properties natural hCPS, particularly since, to minimize enzyme inactivation, the N-terminal $\mathrm{His}_{6}$-tag was not removed. Similarly to liver CPS1, rhCPS1 has an essential requirement for NAG (Fig. 2A). Its specific activity (Table 2) is similar to that reported for liver-isolated human CPS1 [Pierson and Brien, 1980; Rubio et al., 1981]. Apparent $\mathrm{K}_{\mathrm{m}}$ values for ATP, $\mathrm{HCO}_{3}{ }^{-}$and $\mathrm{NH}_{4}{ }^{+}$, and the $\mathrm{K}_{\mathrm{a}}$ for NAG and for the drug analogue of NAG, NCG, are also within published value ranges for natural hCPS1 (Table 2 and Fig. 2) [Pierson and Brien, 1980; Rubio et al., 1981].

rhCPS1 also presents the same oligomeric state as liver-derived hCPS [Rubio et al., 1981]. Gel exclusion chromatography experiments (Fig. 3A) reveal highly similar peaks and estimated masses for the natural human enzyme and for rHCPS1: in both cases the apparent mass 
exceeds by $<30 \%$ that of the monomer, indicating that the enzyme consists of monomers in rapid equilibrium with dimers, with strong predominance of the monomers.

\section{Glycerol partially replaces NAG in the activation of human CPS1.}

We also investigated potentially crucial traits of hCPS1 that had not been amenable to investigation until now. Thus, we show here (Fig. 3B, right panel) that hrCPS1 is activated by glycerol in the absence of NAG, whereas in the presence of NAG is inhibited by increasing concentrations of glycerol. Similar observations had been made with rat liver CPS1 (Fig. 2B, left panel and [Britton et al., 1981; Rubio et al., 1983b]). The substantial activation attained with glycerol and the fact that this polyol appears to activate CPS1 without specifically binding to the NAG site [Rubio et al., 1983b] make conceivable the possibility of developing treatments for CPS1D patients with a damaged NAG site, in which CPS1 could be activated by compounds that do not bind to the NAG site.

\section{Limited proteolysis reveals the hCPS1 domain organization.}

The domain composition of hCPS1 had not been made amenable to investigation until now. The structure of E. coli CPS [Thoden et al., 1997] had revealed a multidomain organization that was anticipated [Rubio, 1993] by the results of limited proteolysis and of other studies with rodent and E. coli CPSs [Cervera et al., 1993; Evans and Balon, 1988; Marshall and Fahien, 1988; Powers-Lee and Corina, 1986; Rodríguez-Aparicio et al., 1989; Rubio et al., 1991]. Limited proteolysis studies with rodent CPS1 revealed four points of preferential proteolytic cleavage that appear to correspond to exposed sequences linking adjacent globular domains, and which are differentially cleaved by elastase, trypsin and chymotrypsin [Powers-Lee and Corina, 
1986; Marshall and Cohen, 1988] (Fig. 1). We observed limited tryptic or elastase digestion patterns with hrCPS1 that fully comply with the reported fragmentation patterns for rat liver CPS1 (Figs. 1B and C) [Marshall and Fahien, 1988; Powers-Lee and Corina, 1986]. These findings support the existence of the same domain organization and architecture in human and rat CPS1, also supporting the similarity of this architecture with that of E. coli CPS [Rubio et al., 1991; Thoden et al., 1997]. Interestingly, as with rat liver CPS1 [Marshall and Fahien, 1988], chymotrypsin inactivated rhCPS1 (Fig. 1D, plot) while decreasing very little CPS1 polypeptide size (Fig. 1D, gels), in agreement with prior experiments with rat liver CPS1 that showed that the enzyme is cleaved very close to its C-terminus [Marshall and Fahien, 1988].

\section{Testing the effects of clinical CPS1D mutations on enzyme functionality}

The present results show that the properties of rhCPS1 mirror those of natural CPS1, supporting the use of rhCPS1 for testing the impact of clinical mutations on enzyme function and stability. We demonstrate this use here with eight missense mutations found in seven neonatal CPS1D patients (Table 1 and Fig. 1A) [Eeds et al., 2006; Finckh et al., 1998; Kurokawa et al., 2007; Summar, 1998] and with two trivial polymorphisms (Table 1 and Fig. 1A) [Finckh et al., 1998; Summar et al., 2003]. Of these ten amino acid substitutions, two map in the bicarbonate phosphorylation domain (a catalytic domain) and are therefore likely to hamper activity. The other eight changes were selected because they map in CPS1 regions of unclear or unique function for which bacterial CPS would not be a good model. Thus, four of them map in the Glnase-like subdomain and another four in the C-terminal domain (Fig. 1A). In any case, E. coli CPS would not have been an optimal model for nine of these amino acid substitutions, since only one affected residue is strictly conserved in all CPSs (Table 1). 
As expected, the polymorphisms p.Thr344Ala $(\mathrm{c} .1030 \mathrm{~A}>\mathrm{G})$ and p.Gly1376Ser (c.4126G $>$ A), mapping respectively in the Glnase-like and the NAG-binding domains (Fig. 1A), caused no negative effects on enzyme production (Fig. 4A), activity (Fig. 4C), kinetic parameters for each substrate or for NAG (Table 3), or on thermal stability (Fig. 4D). In contrast, two clinical mutations affecting respectively these same regions, p.Leu390Arg (c.1169T $>$ G) and p.Leu1381Ser (c.4142T>C) (Fig. 1A), were clearly disease-causing, since they induced strong CPS1 instability as revealed by western blotting of insect cell extracts that showed (Fig. 4B) proteolytic digestion bands instead of the clear-cut CPS1 band observed with the wild-type enzyme. Indeed, these two mutations, which replace hydrophobic residues (residues of hydrophobic nature are found at these positions in all known CPS sequences, Table 1) by polar residues of larger (p.Leu390Arg) or smaller (p.Leu1381Ser) size, were predicted by the MutPred server to be associated with loss of stability (Table 1).

The other six mutations studied (Table 1) were sufficiently stable to allow purification (Fig. 4A). The p.Ala438Pro (c.1313G $>$ C) and p.Thr544Met (c.1631C $>$ T) mutations, which affect the bicarbonate-phosphorylation domain, and the p.Thr1443Ala (c.4327A $>$ G) mutation, which affects the C-terminal domain, greatly decreased enzyme activity, to undetectable or nearly undetectable values (Fig. 4C), clearly indicating that they are disease-causing. Although having no detectable activity in the assay for the complete reaction (detection limit, $1 \%$ of the activity of wild-type rhCPS1), the p.Ala438Pro mutant catalyzed the partial reaction of ATP synthesis from ADP and CP (not shown) that is the reversal of the final step of the CPS1 reaction (a three-step reaction: 1- bicarbonate phosphorylation; 2- carbamate production from carboxyphosphate and ammonia; and 3-carbamate phosphorylation) but, as expected from the domain that is affected by the mutation, it failed to catalyze the bicarbonate-dependent ATPase 
partial reaction that reflects the bicarbonate phosphorylation step [Metzenberg et al., 1958; Rubio et al. 1981].

The large decrease in the activity of the p.Thr544Met mutant was shown to be due (Table 3 and Fig. 2) to the combination of a $\sim 60$-fold increase in the apparent $K_{m}$ for bicarbonate, $a \sim 20$ fold increase in the $\mathrm{K}_{\mathrm{a}}$ for NAG and a $\sim 4$-fold respective decrease and increase in the apparent $\mathrm{V}_{\max }$ and $\mathrm{K}_{\mathrm{m}}$ for ammonia. Except the increase in the $\mathrm{K}_{\mathrm{a}}^{\mathrm{NAG}}$, these kinetic aberrations stem from the fact that this mutation affects a domain that catalyzes the initial two steps of the reaction, involving as substrates ATP, bicarbonate (step 1) and ammonia (step 2) [Rubio 1993; Thoden et al., 1997]. The increased $\mathrm{K}_{\mathrm{a}}^{\mathrm{NAG}}$ cannot be attributed to direct changes in the NAG site, which sits on another enzyme domain [Rodríguez-Aparicio et al. 1989], but to the hampering of the crosstalk between the bicarbonate phosphorylation domain and the NAG binding domain that results in a large increase in affinity for NAG when both ATP and bicarbonate are bound [Alonso and Rubio, 1983].

The decrease in enzyme activity caused by the p.Thr1443Ala mutation, (Fig. 4C) is accounted by a nearly 200 -fold increase in the $\mathrm{K}_{\mathrm{a}}^{\mathrm{NAG}}$ and by a nearly 10 -fold decrease in the apparent $\mathrm{V}_{\max }$ (Table 3 and Fig. 2A). The localization of the NAG-binding domain justifies these effects if the mutation hampers NAG binding and the transmission of the regulatory signal from the NAG site to both phosphorylation domains. Indeed, the two partial reactions of the enzyme, which reflect the two phosphorylation steps, were undetectable in this mutant (results not shown).

The other three mutations examined here, p.Asn355Asp (c.1063A>G) and p.Tyr389Cys (c.1166A $>$ G) which affect the Glnase-like domain and coexist in patient 1, and p.Ala1378Thr (c.4132G>A), which maps on the NAG-binding domain, appear to have too little an effect on 
enzyme activity or on kinetic parameters to justify the neonatal deficiency (Fig. 4C, Table 3). The largest changes observed with these mutations were a 4-fold decrease in $\mathrm{V}_{\max }$ and a nearly 3-fold increase in the $\mathrm{K}_{\mathrm{a}}$ for NAG, occuring with the p.Asn355Asp mutation (Table 3). However, thermal inactivation assays (Fig. 4D) revealed that these mutations substantially decreased the thermal stability of rhCPS1, particularly p.Asn355Asp, which lowered $\sim 11^{\circ} \mathrm{C}$ the midinactivation temperature. In contrast, the temperature dependence of enzyme inactivation was identical for the two polymorphisms and for the wild-type enzyme (Fig. 4D). The combined effects of the decrease in $\mathrm{V}_{\max }$ and the modest increase in $\mathrm{K}_{\mathrm{a}}{ }^{\mathrm{NAG}}$ with the p.Asn355Asp mutant, together with the decreased enzyme stability, may result in enzyme deficiency. This may also be the case with the p.Tyr389Cys mutation, which decreased $40 \%$ enzyme activity (Fig. 4C) and caused a substantial, although less drastic effect on thermal inactivation. Finally, with p.Ala1378Thr, the deficiency could be due to the combination of the decreased stability and a twofold increase in apparent $\mathrm{K}_{\mathrm{m}}$ for ATP (Table 3). The fact that these last two mutations are, respectively, only one and three positions away from Leu390 and Leu1381, two residues for which their p.Leu390Arg and p.Leu1381Ser mutations were found to cause dramatic loss of enzyme stability (see above), lends further support to the view that these mutations may hamper sufficiently enzyme stability "in vivo" to cause enzyme deficiency.

\section{Influence of the substrates and of NAG on the resistance of human CPS1 to proteolytic or thermal inactivation}

From all of the above, enzyme destabilization appears a crucial element in the causation of CPS1D with five of the eight missense mutations studied here (p.Asn355Asp, p.Tyr389Cys, p.Leu390Arg, p.Ala1378Thr and p.Leu1381Ser). Therefore, enzyme stabilization by ligands 
acting as chemical chaperones could be a useful future treatment of CPS1D. Similarly to the observation that chaperoning of phenylalanine hydroxylase by its essential cofactor tetrahydrobiopterin is clinically useful in phenylketonuria [Erlandsen et al., 2004], the CPS1 substrates and particularly the CPS1 allosteric activator NAG and its pharmacological deacylaseresistant analog and orphan drug NCG could afford some protection of CPS1. We tested the effects of these ligands on the sensitivity of rhCPS1 to proteolytic inactivation by elastase. These experiments are based on previous data on the sensitivity of the rodent liver enzyme to elastase and on the effects on that sensitivity of enzyme ligands [Evans \& Balon, 1988; Guadalajara et al., 1983; Marshall \& Fahien, 1988; Powers-Lee \& Corina, 1986]. Figs. 5 A and B reveal a strong influence of NAG and NCG on elastase inactivation of rhCPS1. Whereas these two compounds alone accelerated rhCPS1 inactivation in this system (Fig. 5A), when they were added together with MgATP, the enzyme became nearly entirely protected against even very large elastase concentrations (Fig. 5B). MgATP alone did not cause such large protection. Similarly, the combination of MgATP and NAG or MgATP and NCG was highly effective in protecting the enzyme from thermal inactivation (Fig. 5C). In this case MgATP also substantially protected the enzyme, although the highest degree of protection was attained with MgATP together with NAG or NCG. We also showed in these experiments that glycerol at a concentration (20\%) at which it causes maximal NAG-independent CPS1 activation (Fig. 3D) also protected substantially the enzyme from thermal inactivation (Fig. 5C). Interestingly, the protecting effects of NAG/MgATP, NCG/MgATP, MgATP and glycerol were also patent when a mutant (p.Ala1378Thr) exhibiting reduced thermal stability was studied (Fig. 5D).

In the matrix of liver mitochondria, where CPS1 is localized, MgATP is likely to be abundant under most circumstances, but NAG may not, particularly under conditions of protein 
restriction as when a urea cycle deficiency is suspected. Therefore, under these circumstances the administration of NCG might help protect the enzyme from thermal inactivation or from proteolytic degradation. Therefore, studies on the effects of NCG on CPS1 stability "in vivo" are warranted. Indeed, a genetically demonstrated CPS1D patient has been documented to respond to NCG administration [Williams et al., 2010].

\section{Final comments}

rhCPS1 is shown here to mirror the natural human enzyme or the rat liver enzyme in all aspects analyzed, including substrate and activator kinetics, oligomeric form, domain composition, sensitivity to proteases and protection thereof by ligands, and ability of glycerol to replace NAG as a CPS1 activator. Our confirmation that the domain organization is that reported for other CPSs supports the present structural rationalizations of the effects of missense changes in CPS1 [Häberle et al., 2011; Martínez et al., 2010]. Since recombinant production of hCPS1 permits the introduction of amino acid changes at will, the way is now open for testing the functional impact of missense mutations found in CPS1D. It would be desirable to compare the present system and even to complement it with the one using Schyzosaccharomyces pombe as the expression host of hCPS1 [Ahuja and Powers-Lee, 2008]. Although data on this system are very limited, the simultaneous use of both expression systems may prove desirable for maximizing the number of clinical mutants that can be tested. After all, both expression systems are heterologous with respect to hCPS1 and therefore the possibility cannot be excluded that some mutant forms can be expressed in one system but not in the other.

With the present system, clear-cut correlations between given missense mutations and specific molecular phenotypes can be established, hopefully shedding light on the degree of 
severity of different mutations. Indeed, the lack of detectable effects of the two polymorphisms studied here, and the severity of the effects demonstrated for six of the eight mutations analyzed, clearly indicate that the experimental studies with rhCPS1 mutants expressed "in vitro" identify disease-causing mutations. Even with the two mutations that caused the less drastic effects, they triggered some negative changes on enzyme activity and/or stability that were not observed with the two polymorphisms. In any case, the extension of the present pilot study to larger series of clinical CPS1D mutations should permit deeper ascertaining of the sensitivity of our approach to identify disease-causing mutations and for estimating their actual severity.

Our results shed also light on the role of the Glnase-like domain of CPS1 and on the reasons for its preservation despite the fact that CPS1 does not use glutamine [Rubio et al., 1981]. The observations that the amino acid substitutions p.Asn355Asp and p.Tyr398Cys, mapping in the Glnase-like domain of CPS1 (Fig. 1A), do not inactivate CPS1 or cause dramatic changes in $\mathrm{K}_{\mathrm{m}}$ values for the substrates (Table 3), agrees with the general belief that this domain is not directly involved in the enzyme reaction. However, these mutations, as well as another two mutations (p.S123F and p.H337R) introduced previously in the N-terminal region of rat CPS1 [Pekkala et al., 2010] resulted in 40-75\% reduction in enzyme activity (see for the present mutations Fig. 4C). These results also agree with a study [Ahuja and Powers-Lee, 2008] in which hCPS1 lacking the entire N-terminal region exhibited a 700-fold reduction in enzyme activity, although the very drastic change of deleting $25 \%$ of the protein molecule may render difficult the interpretation of this extreme degree of inactivation. In any case, the changes revealed by our present studies and by earlier studies with single amino acid substitutions affecting this CPS1 domain clearly support an activating role of this N-terminal region on $\mathrm{CP}$ synthesis, which is catalyzed by the C-terminal moiety of the enzyme [Cervera et al., 1993; Rubio, 1993]. Such 
activation appears reminiscent of the one caused by the small subunit of E. coli CPS on the catalysis by the large subunit of the reaction from ammonia [Meister, 1989]. The Glnase-like domain also stabilizes the enzyme, since the p.Leu390Arg, p.Asn355Asp and p.Tyr389Cys mutations decrease CPS1 stability. Again this role is reminiscent of the strong stabilization triggered in E. coli CPS upon association of the small and large subunits [Cervera et al., 1993]. The activation of CP synthesis, and the enhanced enzyme stability, may be sufficiently important advantages to warrant retention of the N-terminal region in CPS1.

Our present findings also shed light on the roles of the C-terminal domain. We localized "in silico" the NAG site in the crystal structure of this domain [Pekkala et al., 2009], providing as experimental support for this localization the results of photoaffinity labeling with $\mathrm{N}$ chloroacetyl-L-glutamate and of site-directed mutagenesis of rat liver CPS1 [Pekkala et al., 2009]. We now provide even more direct proof for such localization with hCPS1, the enzyme for which the crystal structure of the C-terminal domain was determined. Thus, among all the mutations studied here, the one mapping closest to the proposed NAG site, p.Thr1443Ala, produces by far the most drastic decrease in the apparent affinity for NAG (two orders of magnitude decrease) (Table 3). In our proposed NAG binding site [Pekkala et al., 2009], Thr1443 is close to the bound activator, adjacent to a residue of the NAG site and to one of the three lid residues that cover the bound NAG molecule (Supp. Fig. S2). The importance of Thr1443 for effector regulation of CPS1 is highlighted also by the observation that phosphorylation of the equivalent residue in hamster CPSII (a component of CAD, the trifunctional enzyme involved in pyrimidine biosynthesis), Ser1406 [Simmer et al., 1990], hampers CPSII allosteric regulation by its negative effector UTP [Carrey et al., 1985]. As NAG in CPS1, UTP binds to the C-terminal domain of CPSII [Liu et al. 1994]. 
The present data also evidence that the C-terminal domain is an important determinant for CPS1 stability, since two mutations mapping in this domain, p.Ala1378Thr and p.Leu1381Ser, which affect the inner face of a helix from the outer layer of the $\alpha \beta \alpha$ sandwich conforming this domain (Supp. Fig. S2), substantially or very drastically destabilized the enzyme. This important impact on enzyme stability clearly supports a high degree of integration of the C-terminal domain in the CPS1 architecture. Thus, despite the multidomain character of CPS1, the architecture of this enzyme would appear to be highly cooperative, explaining the influence of NAG binding on events that occur far away from the C-terminal domain, such as the activation of both phosphorylation domains [Rubio et al., 1983a].

\section{ACKNOWLEDGMENTS}

Supported by grants from the Fundación Alicia Koplowitz 2011, Prometeo 2009/051 from the Valencian Government, and BFU2011-30407 and SAF2010-17933 from the Science Department of the Spanish Government. CD and AIM had FPU (Spanish Government) and CIPF-Bancaixa fellowships.

\section{REFERENCES}

Adzhubei IA, Schmidt S, Peshkin L, Ramensky VE, Gerasimova A, Bork P, Kondrashov AS, Sunyaev SR. 2010. A method and server for predicting damaging missense mutations. Nature Methods 7:248-249.

Ahuja V, Powers-Lee SG. 2008. Human carbamoyl-phosphate synthetase: insight into Nacetylglutamate interaction and the functional effects of a common single nucleotide polymorphism. J Inherit Metab Dis 31:481-491. 
Alonso E, Girbés J, García-España A, Rubio V. 1989. Changes in urea cycle-related metabolites in the mouse after combined administration of valproic acid and an amino acid load. Arch Biochem Biophys 272:267-273.

Alonso E, Cervera J, García-España A, Bendala E, Rubio V. 1992. Oxidative inactivation of carbamoyl phosphate synthetase (ammonia). Mechanism and sites of oxidation, degradation of the oxidized enzyme, and inactivation by glycerol, EDTA, and thiol protecting agents. $\mathrm{J}$ Biol Chem 267:4524-4532.

Alonso E, Rubio V. 1983. Binding of N-acetyl-L-glutamate to rat liver carbamoyl phosphate synthetase (ammonia). Eur J Biochem 135:331-337.

Amero SA, James TC, Elgin SC. 1994. Production of antibodies using proteins in gel bands. Methods Mol Biol 32:401-406.

Barcelona-Andrés B, Marina A, Rubio V. 2002. Gene structure, organization, expression, and potential regulatory mechanisms of arginine catabolism in Enterococcus faecalis. $\mathrm{J}$ Bacteriol 184:6289-6300.

Bradford MM. 1976. A rapid and sensitive method for the quantitation of microgram quantities of protein utilizing the principle of protein-dye binding. Anal Biochem 72:248-254.

Britton HG, Rubio V, Grisolia S. 1981. Synthesis of carbamoyl phosphate by carbamoyl phosphate synthetase I in the absence of acetylglutamate. Activation of the enzyme by cryoprotectants. Biochem Biophys Res Commun 99:1131-1137.

Brusilow SW, Horwich AL. 2001. Urea cycle enzymes. In: Scriver CR, Beaudet AL, Sly WS, Valle D, editors; Child B, Kinzler KW, Vogelstein B, associated editors. The Metabolic and Molecular Bases of Inherited Disease, 8e. New York: McGraw-Hill. Vol 2, p 1909-1963. 
Carrey EA, Campbell DG, Hardie DG. 1985. Phosphorylation and activation of hamster carbamyl phosphate synthetase II by cAMP-dependent protein kinase. A novel mechanism for regulation of pyrimidine nucleotide biosynthesis. EMBO J 4:3735-3742.

Cervera J, Conejero-Lara F, Ruiz-Sanz J, Galisteo ML, Mateo PL, Lusty CJ, Rubio V. 1993. The influence of effectors and subunit interactions on Escherichia coli carbamoyl-phosphate synthetase studied by differential scanning calorimetry. J Biol Chem 268:12504-12511.

Eeds AM, Hall LD, Yadav M, Willis A, Summar S, Putnam A, Barr F, Summar ML. 2006. The frequent observation of evidence for nonsense-mediated decay in RNA from patients with carbamyl phosphate synthetase I deficiency. Mol Genet Metab 89:80-86.

Erlandsen H, Pey AL, Gámez A, Pérez B, Desviat LR, Aguado C, Koch R, Surendran S, Tyring S, Matalon R, Scriver CR, Ugarte M et al. (2004) Correction of kinetic and stability defects by tetrahydrobiopterin in phenylketonuria patients with certain phenylalanine hydroxylase mutations. Proc Natl Acad Sci U S A. 101:16903-16908.

Evans DR, Balon MA. 1988. Controlled proteolysis of ammonia-dependent carbamoylphosphate synthetase I from Syrian hamster liver. Biochim Biophys Acta 953:185-196.

Finckh U, Kohlschutter A, Schafer H, Sperhake K, Colombo JP, Gal A. 1998. Prenatal diagnosis of carbamoyl-phosphate synthetase I deficiency by identification of a missense mutation in CPS1. Hum Mutat 12:206-211.

Guadalajara AM, Rubio V, Grisolía S. 1983. Inactivation of carbamoyl phosphate synthetase (ammonia) by elastase as a probe to investigate binding of the substrates. Biochem Biophys Res Commun. 117:238-244. 
Guthöhrlein G, Knappe J. 1968. Structure and function of carbamoylphosphate synthase. I. Transitions between two catalytically inactive forms and the active form. Eur $\mathrm{J}$ Biochem $7: 119-127$

Häberle J, Shchelochkov OA, Wang J, Katsonis P, Hall L, Reiss S, Eeds A, Willis A, Yadav M, Summar S; Urea Cycle Disorders Consortium, Lichtarge O et al. 2011. Molecular defects in human carbamoyl phosphate synthetase I: mutational spectrum, diagnostic and protein structure considerations. Hum Mutat 32:579-585.

Häberle J, Boddaert N, Burlina A, Chakrapani A, Dixon M, Huemer M, Karall D, Martinelli D, Sanjurjo Crespo P, Santer R, Servais A et al.. 2012. Suggested Guidelines for the Diagnosis and Management of Urea Cycle Disorders. Orphanet J Rare Dis 7:32.

Haraguchi Y, Uchino T, Takiguchi M, Endo F, Mori M, Matsuda I. 1991. Cloning and sequence of a cDNA encoding human carbamyl phosphate synthetase I: molecular analysis of hyperammonemia. Gene 107:335-340.

Kurokawa K, Yorifuji T, Kawai M, Momoi T, Nagasaka H, Takayanagi M, Kobayashi K, Yoshino M, Kosho T, Adachi M, Otsuka H, Yamamoto S, et al.. 2007. Molecular and clinical analyses of Japanese patients with carbamoylphosphate synthetase 1 (CPS1) deficiency. J Hum Genet 52:349-354.

Laemmli UK. 1970. Cleavage of structural proteins during the assembly of the head of bacteriophage T4. Nature 227:680-685.

Li B, Krishnan VG, Mort ME, Xin F, Kamati KK, Cooper DN, Mooney SD, Radivojac P. 2009. Automated inference of molecular mechanisms of disease from amino acid substitutions. Bioinformatics 25: 2744-2750. 
Liu X, Guy HI, Evans DR. 1994. Identification of the regulatory domain of the mammalian multifunctional protein $\mathrm{CAD}$ by the construction of an Escherichia coli hamster hybrid carbamyl-phosphate synthetase. J Biol Chem 269:27747-27755.

Marshall M, Cohen PP. 1972. Ornithine transcarbamylase from Streptococcus faecalis and bovine liver. I. Isolation and subunit structure. J Biol Chem. 247:1641-1653.

Marshall M, Fahien LA. 1985. Proximate sulfhydryl groups in the acetylglutamate complex of rat carbamylphosphate synthetase I: their reaction with the affinity reagent 5'-pfluorosulfonylbenzoyladenosine. Arch Biochem Biophys 241:200-214.

Marshall M, Fahien LA. 1988. Proteolysis as a probe of ligand-associated conformational changes in rat carbamyl phosphate synthetase I. Arch Biochem Biophys 262:455-470.

Martínez AI, Pérez-Arellano I, Pekkala S, Barcelona B, Cervera J. 2010. Genetic, structural and biochemical basis of carbamoyl phosphate synthetase 1 deficiency. Mol Genet Metab 101:311-323.

Meister A. 1989. Mechanism and regulation of the glutamine-dependent carbamyl phosphate synthetase of Escherichia coli. Adv Enzymol Relat Areas Mol Biol 62:315-374.

Metzenberg RL, Marshall M, Cohen PP. 1958. Carbamyl phosphate synthetase: studies on the mechanism of action. J Biol Chem 233:1560-1564.

Nyunoya H, Broglie KE, Widgren EE, Lusty CJ. 1985. Characterization and derivation of the gene coding for mitochondrial carbamyl phosphate synthetase I of rat. J Biol Chem 260:9346-9356.

Pearson DL, Dawling S, Walsh WF, Haines JL, Christman BW, Bazyk A, Scott N, Summar ML. 2001. Neonatal pulmonary hypertension--urea-cycle intermediates, nitric oxide production, and carbamoyl-phosphate synthetase function. N Engl J Med. 344:1832-1838. 
Pekkala S, Martinez AI, Barcelona B, Gallego J, Bendala E, Yefimenko I, Rubio V, Cervera J. 2009. Structural insight on the control of urea synthesis: identification of the binding site for $\mathrm{N}$-acetyl-L-glutamate, the essential allosteric activator of mitochondrial carbamoylphosphate synthetase1. Biochem J 424:211-220.

Pekkala S, Martínez AI, Barcelona B, Yefimenko I, Finckh U, Rubio V, Cervera J. 2010. Understanding carbamoyl-phosphate synthetase I (CPS1) deficiency by using expression studies and structure-based analysis. Hum Mutat 31:801-808.

Pierson DL, Brien JM. 1980. Human carbamylphosphate synthetase I. Stabilization, purification, and partial characterization of the enzyme from human liver. J Biol Chem 255:7891-7895.

Powers-Lee SG, Corina K. 1986. Domain structure of rat liver carbamoyl phosphate synthetase I. J Biol Chem 261:15349-15352.

Raijman L, Jones ME. 1976. Purification, composition, and some properties of rat liver carbamyl phosphate synthetase (ammonia). Arch Biochem Biophys 175:270-278.

Rodriguez-Aparicio LB, Guadalajara AM, Rubio V. 1989. Physical location of the site for Nacetyl-L-glutamate, the allosteric activator of carbamoyl phosphate synthetase, in the 20kilodalton COOH-terminal domain. Biochemistry 28:3070-3074.

Rubio V. 1993. Structure-function studies in carbamoyl phosphate synthetases. Biochem Soc Trans 21:198-202.

Rubio V, Britton HG, Grisolia S. 1983a. Mitochondrial carbamoyl phosphate synthetase activity in the absence of $\mathrm{N}$-acetyl-L-glutamate. Mechanism of activation by this cofactor. Eur $\mathrm{J}$ Biochem 134:337-343.

Rubio V, Britton HG, Grisolía S. 1983b. Activation of carbamoyl phosphate synthetase by cryoprotectants. Mol Cell Biochem 53-54:279-298. 
Rubio V, Cervera J, Lusty CJ, Bendala E, Britton HG. 1991. Domain structure of the large subunit of Escherichia coli carbamoyl phosphate synthetase. Location of the binding site for the allosteric inhibitor UMP in the COOH-terminal domain. Biochemistry 30:1068-1075.

Rubio V, Ramponi G, Grisolia S. 1981. Carbamoyl-phosphate synthetase I of human liver. Purification, some properties and immunological cross-reactivity with the rat liver enzyme. Biochim Biophys Acta 659:150-160.

Ryall J, Nguyen M, Bendayan M, Shore GC. 1985. Expression of nuclear genes encoding the urea cycle enzymes, carbamoyl-phosphate synthetase I and ornithine carbamoyl transferase, in rat liver and intestinal mucosa. Eur J Biochem 152:287-292.

Shih VE. 1976 Congenital hyperammonemic syndromes. Clin Perinatol 3:3-14.

Simmer JP, Kelly RE, Rinker AG Jr, Scully JL, Evans DR. 1990. Mammalian carbamyl phosphate synthetase (CPS). DNA sequence and evolution of the CPS domain of the Syrian hamster multifunctional protein CAD. J Biol Chem 265:10395-10402.

Summar ML. 1998. Molecular genetic research into carbamoyl-phosphate synthase I: molecular defects and linkage markers. J Inherit Metab Dis 21 Suppl 1:30-39.

Summar ML, Dasouki MJ, Schofield PJ, Krishnamani MR, Vnencak-Jones C, Tuchman M, Mao J, Phillips JA 3rd. 1995. Physical and linkage mapping of human carbamyl phosphate synthetase I (CPS1) and reassignment from 2p to 2q35. Cytogenet Cell Genet 71:266-267.

Summar ML, Hall LD, Eeds AM, Hutcheson HB, Kuo AN, Willis AS, Rubio V, Arvin MK, Schofield JP, Dawson EP. 2003. Characterization of genomic structure and polymorphisms in the human carbamyl phosphate synthetase I gene. Gene 311:51-57. 
Thoden JB, Holden HM, Wesenberg G, Raushel FM, Rayment I. 1997. Structure of carbamoyl phosphate synthetase: a journey of $96 \AA$ from substrate to product. Biochemistry 36:63056316.

Williams M, Huijmans JGM, van Diggelen OP, van der Low EJTM, de Klerk JBC, Haeberle J (2010) Carbamoyl phosphate synthetase I (CPS 1) deficiency: treatment with carglumic acid (Carbaglu) J Inherit Metab Dis 33 (Suppl 1):S118

Yefimenko I, Fresquet V, Marco-Marín C, Rubio V, Cervera J. 2005. Understanding carbamoylphosphate synthetase deficiency: impact of clinical mutations on enzyme functionality. J Mol Biol 349:127-141. 


\section{LEGENDS TO FIGURES}

Figure 1. Domain composition of human CPS1. A: Linear scheme of mature CPS1, highlighting four interdomain linkers that are cleaved by the indicated proteases as identified in rodent CPS1, with the corresponding fragments masses (in $\mathrm{kDa}$ ) above them [Marshall and Fahien, 1988]. Chymo, chymotrypsin. Trypsin(2) denotes cleavage after scission at the other tryptic site. The bars shaded grey schematize the 40-kDa N-terminal and the 120-kDa C-terminal CPS1 moieties that correspond to the small and large subunits of E. coli CPS, respectively. Polyclonal rabbit antibodies raised against these isolated moieties are called Anti-40 and Anti-120. Functional domains are shown in background texture and are identified. Glnase-like corresponds to the Glnase domain of bacterial CPS, but has no known function in CPS1. ??, unknown function. A dashed line separates two domains composing a proteolytic domain. The two polymorphisms (in italic and grey background) and the eight clinical mutations studied here are mapped in the CPS1 polypeptide with banners. B, C and D: Top part, fragments generated with trypsin, elastase or chymotrypsin [Marshall and Fahien, 1988]. The cleavage points are identified with the ABCD notation used in panel A. Each tryptic fragment is called T1-T3, elastase fragments E1-E4 and the chymotryptic one $\mathrm{C} 1$. Their approximate masses and their reactivity with Anti-40 and Anti120 antibodies are given. The $20 \mathrm{kDa}$ C-terminal fragment is rapidly degraded [Marshall and Fahien, 1988] and is shown crossed. Lower parts, SDS-PAGE of digested recombinant human CPS1 and, for comparison, of rat liver CPS1, stained with Coomassie or by immunoperoxidase with Anti-40 or Anti-120 after western blotting (only done with the rat enzyme). Digestions of CPS1 $(1.3-2 \mathrm{mg} / \mathrm{ml})$ were at $37^{\circ}$, for $15-30 \mathrm{~min}$ with the indicated protease $(4-16 \mu \mathrm{g} / \mathrm{ml}$; pancreatic, from Boheringer Mannheim or Sigma) in $35 \mathrm{mM}$ Tris- $\mathrm{HCl} \mathrm{pH} 7.4,9 \%$ glycerol, 1.5 
$\mathrm{mM}$ DTT, $20 \mathrm{mM} \mathrm{KCl}$ and $10 \mathrm{mM}$ NAG. The enzyme was preincubated at least $15 \mathrm{~min}$ at $37^{\circ} \mathrm{C}$ prior to the addition of the protease. This addition was considered time zero. Fragments are identified in the gels as T1-T3, E1-E4 or C1. Note in (D) that while chymotrypsin inactivates rat and human CPS1 (see the plot), there is little decrease ( $2 \mathrm{kDa})$ in polypeptide mass (top panels), corresponding to the loss of approximately 12 residues from the enzyme C-terminus documented earlier for rat CPS1 [Marshall and Fahien, 1988].

Figure 2. Dependence of CPS1 activity on the concentrations of NAG and bicarbonate for nonmutated (WT) CPS1 and for the indicated mutant forms. The curves fitted to the data are hyperbolae for the kinetic constants given in Table 3. The insets expand the curves for the mutants, to demonstrate the hyperbolic kinetics despite the decreased activity. A: NAG varied. In the case of the p.Thr544Met mutant the concentration of bicarbonate was fixed at $0.5 \mathrm{M}$. B: bicarbonate varied.

Figure 3. Recombinant human CPS1 replicates the natural enzyme in the oligomeric state and the ability to be activated and inhibited by glycerol. A: Gel exclusion chromatography analysis. The upper lines are the semilogarithmic plots of the masses of marker proteins (closed circles) versus their elution volumes. Peaks of CPS1 activity (left panel, open symbols) or of CPS1 protein (peak in the right panel) are shown below them. The mass of CPS1, estimated by interpolation, is shown above a vertical line emerging from the peak. Left panel, results with the enzyme purified from human liver [Rubio et al., 1981], using a conventional $0.9 \times 56 \mathrm{~cm}$ column of Sephadex G-200 run at $23^{\circ} \mathrm{C}$. For further details, including the list and masses of standards used, see [Rubio et al., 1981]. Right panel, present results with the recombinant human enzyme 
under essentially the same conditions as those in [Rubio et al., 1981] except for the use of a Superdex 200HR (10/300) column mounted on an Äkta fast protein liquid chromatography system, at a flow rate of $0.5 \mathrm{ml} / \mathrm{min}$, the application of $0.02 \mathrm{ml}$ of a $3 \mathrm{mg} / \mathrm{ml}$ solution of human recombinant CPS1 or appropriate amounts of protein standards, and the continuous monitoring of the optical absorption at $280 \mathrm{~nm}$. Protein standards for this panel were (masses are given in parenthesis, in $\mathrm{kDa}$ ) bovine pancreatic ribonuclease A (13.7), bovine serum albumin (66.4), yeast alcohol dehydrogenase dimer (73.4) and tetramer (146.8), $\beta$-amylase (223.8) and ferritin (440). B: Effects of the addition of glycerol on CPS1 activity in the presence or in the absence of 10 mM NAG as indicated (closed and open circles, respectively). Velocities, measured as ADP production, are expressed as a percentage of the velocity in the presence of $10 \mathrm{mM}$ NAG and in the absence of glycerol. Left and right panels, results with the rat liver enzyme and with the recombinant human enzyme, respectively.

Figure 4. Production and properties of the enzyme forms with the amino acid substitutions studied here. A: SDS-PAGE (8\% polyacrylamide, Coomassie staining) of purified human recombinant CPS1, either wild-type (WT) or carrying the indicated mutations. Polymorphisms are shown in italic script and underlined. St, protein markers with masses indicated on the side. B: Western blot of cell extracts ( $20 \mu \mathrm{g}$ protein per well) of Sf9 cells infected with baculoviruses encoding either wild-type human CPS1 or its p.Leu390Arg or p.Leu1381Ser mutants. A polyclonal rabbit antiserum against rat liver CPS1 was used for immunostaining. C: Enzyme activity (standard assay conditions) of the purified wild-type or mutant human CPS1 forms. The bars for the wild-type enzyme, for the two polymorphisms and for the forms carrying clinical 
mutations are filled in white, checkerboard and black, respectively. Error bars give standard errors. D: Thermal stability of wild-type recombinant CPS1, and of the forms carrying either the polymorphisms (in italic and underlined), or the indicated clinical mutations. The enzyme, at 0.5 $1 \mathrm{mg} / \mathrm{ml}$ in a solution of $50 \mathrm{mM}$ glycyl-glycine $\mathrm{pH} 7.4,20 \mathrm{mM} \mathrm{KCl}$ an $20 \%$ glycerol, was heated $15 \mathrm{~min}$ at the indicated temperature, then rapidly cooled to $0^{\circ} \mathrm{C}$, and its activity determined immediately at $37^{\circ} \mathrm{C}$. The horizontal dashed line marks $50 \%$ inactivation, whereas the vertical dashed lines cross the $\mathrm{X}$-axis at the temperature at which $50 \%$ inactivation occurs for each enzyme form.

Figure 5. Effects of ligands on the inactivation of rhCPS1 by elastase or by heating. When indicated, NAG, NCG and ATP were added, at $10 \mathrm{mM}$ concentrations. When ATP was added, $\mathrm{MgSO}_{4}$ was also added at a concentration of $20 \mathrm{mM}$. Incubations were terminated by dilution in the continuous enzyme activity assay, monitoring ADP production at $37^{\circ} \mathrm{C}$. Results are given as percentages of the activity not having undergone the corresponding proteolytic or heating treatment. A and B: Digestions of rhCPS1 with respective elastase concentrations of $10 \mu \mathrm{g} / \mathrm{ml}$ or $50 \mu \mathrm{g} / \mathrm{ml}$. Other conditions were as in Fig. 1D. C and D: Thermal inactivation of the wild-type or the p.Ala1378Thr mutant forms of rhCPS1 (both used at $0.1 \mathrm{mg} / \mathrm{ml}$ concentrations) after 15min incubation at the indicated temperatures in a solution of $50 \mathrm{mM}$ glycyl-glycine $\mathrm{pH} 7.4,20$ $\mathrm{mM} \mathrm{KCl}, 1 \mathrm{mM}$ DTT with the indicated ligands or with $20 \%$ glycerol. 
Table 1. CPS1 missense mutations found in patients with CPS1 deficiency, and non-synonymous polymorphisms studied experimentally here

\begin{tabular}{|c|c|c|c|c|c|c|c|c|c|c|}
\hline \multirow{2}{*}{ Patient \# } & \multirow[t]{2}{*}{ Allele } & \multirow{2}{*}{$\begin{array}{l}\text { Nucleotide } \\
\text { change }^{\mathrm{a}}\end{array}$} & \multirow[t]{2}{*}{ Amino acid change } & \multicolumn{3}{|c|}{ Amino acid in CPS } & \multirow[t]{2}{*}{ Domain } & \multirow{2}{*}{$\begin{array}{l}\text { PolyPhen-2 } \\
\text { prediction }\end{array}$} & \multicolumn{2}{|c|}{ MutPred prediction } \\
\hline & & & & 1 & III & Other & & & $g$ score & Hypothesis \\
\hline \multicolumn{11}{|c|}{ Clinical mutations } \\
\hline \multirow{2}{*}{$1^{\mathrm{b}}$} & 1 & c. $1063 \mathrm{~A}>\mathrm{G}$ & p.Asn355Asp & $\mathrm{N}$ & $\mathrm{N}$ & Variable & Glnase-like & Probably damag. & \multirow{2}{*}{\multicolumn{2}{|c|}{$\begin{array}{l}0.875 \\
0.835\end{array}$}} \\
\hline & 2 & с. $1166 \mathrm{~A}>\mathrm{G}$ & p.Tyr389Cys & $\mathrm{Y} / \mathrm{F}$ & $\mathrm{Y} / \mathrm{F}$ & Variable & Glnase-like & Possibly damag. & & \\
\hline $2^{b}$ & $\begin{array}{l}1 \\
2\end{array}$ & c. $1169 \mathrm{~T}>\mathrm{G}$ & $\begin{array}{l}\text { p.Leu390Arg } \\
\text { Unknown }\end{array}$ & $\mathrm{L}$ & $\mathrm{L}$ & $\mathrm{L} / \mathrm{I} / \mathrm{F} / \mathrm{V}$ & Glnase-like & Probably damag. & 0.929 & C: Loss stability \\
\hline $3^{c}$ & $\begin{array}{l}1 \\
2\end{array}$ & $\begin{array}{l}\text { c. } 1312 \mathrm{G}>\mathrm{C} \\
\text { c. } 130 \mathrm{C}>\mathrm{T}\end{array}$ & $\begin{array}{l}\text { p.Ala438Pro } \\
\text { p.Gln44* }\end{array}$ & A & A & A & $\mathrm{HCO}_{3}^{-}$phosphorylation & Probably damag. & 0.969 & VC: Loss catalysis \\
\hline $4^{\mathrm{d}}$ & $\begin{array}{l}1 \\
2\end{array}$ & $\begin{array}{l}\text { c. } 1631 \mathrm{C}>\mathrm{T} \\
\text { c. } 1631 \mathrm{C}>\mathrm{T}\end{array}$ & $\begin{array}{l}\text { p.Thr544Met } \\
\text { p.Thr544Met }\end{array}$ & $\mathrm{T}$ & $\mathrm{T}$ & $\mathrm{A} / \mathrm{G} / \mathrm{S} / \mathrm{T}$ & $\mathrm{HCO}_{3}{ }^{-}$phosphorylation. & Possibly damag. & 0.869 & \\
\hline $5^{\mathrm{b}}$ & $\begin{array}{l}1 \\
2\end{array}$ & $\begin{array}{l}\text { c. } 4132 \mathrm{G}>\mathrm{A} \\
\text { c.3185delA }\end{array}$ & $\begin{array}{l}\text { p.Ala1378Thr } \\
\text { p.Asn1062Thrfs*38 }\end{array}$ & A & A & Apolar & NAG-binding & Probably damag. & 0.919 & \\
\hline $6^{\mathrm{e}}$ & $\begin{array}{l}1 \\
2\end{array}$ & c. $4142 \mathrm{~T}>\mathrm{C}$ & $\begin{array}{l}\text { p.Leu1381Ser } \\
\text { Unknown }\end{array}$ & $\mathrm{L}$ & $\mathrm{L}$ & $\mathrm{L} / \mathrm{F} / \mathrm{Y} / \mathrm{A}$ & NAG-binding & Probably damag. & 0.923 & C: Loss stability \\
\hline $7^{\mathrm{b}}$ & $\begin{array}{l}1 \\
2\end{array}$ & $\begin{array}{l}\text { c. } 4327 \mathrm{~A}>\mathrm{G} \\
\text { c. } 3784 \mathrm{C}>\mathrm{T}\end{array}$ & $\begin{array}{l}\text { p.Thr1443Ala } \\
\text { p.Arg1262* }\end{array}$ & $\mathrm{T}$ & $\mathrm{T} / \mathrm{S}$ & Variable & NAG-binding & Possibly damag. & 0.738 & \\
\hline \multicolumn{11}{|c|}{ Polymorphisms } \\
\hline$-{ }^{\mathrm{d}, \mathrm{f}}$ & - & c. $1030 A>G$ & p.Thr344Ala & $\mathrm{T} / \mathrm{S}$ & S & Variable & Glnase-like & Benign & 0.185 & \\
\hline$-{ }^{f}$ & - & c. $4126 \mathrm{G}>\mathrm{A}$ & p.Gly1376Ser & G & A & Variable & NAG-binding & Benign & 0.129 & \\
\hline
\end{tabular}


All patients were reported to exhibit neonatal presentations. Amino acids are shown in three-letter code for the human substitutions and in oneletter code for occurrence in the various CPSs. Variable denotes the occurrence at a given position in the indicated group of CPSs, of $>4$ types of amino acids with no constant chemical characteristics (polar, apolar, charged, etc). When the second allele is not a missense change, no data are given on residue conservation and pathogenicity potential. For localization of the CPS1 domains and the mapping of the mutations in the CPS1 polypeptide, see Fig. 4A. PolyPhen-2 grades the probability of a damaging effect of an amino acid substitution, as probably damaging, possibly damaging and benign. MutPred gave a $g$ score corresponding to the probability that a given amino acid substitution was deleterious/diseaseassociated. When indicated this server was very confident (VC) or confident (C) that the indicated changes caused loss of stability or loss of a catalytic residue.

a cDNA reference sequence NM_001875.4 (GenBank). +1 corresponding to the A of the translation initiation codon in the reference sequence (according to journal guidelines under www.hgvs.org/mutnomen).

${ }^{\mathrm{b}}$ Eeds et al., 2006.

${ }^{\mathrm{c}}$ Kurokawa et al., 2007.

${ }^{\mathrm{d}}$ Finckh et al., 1998.

e Summar, 1998.

${ }^{\mathrm{f}}$ Summar et al., 2003. 
Table 2. Comparison of the activity, the apparent $K_{m}$ values for the substrates and the $K_{a}$ values for $\mathrm{N}$-acetyl-L-glutamate (NAG) or for its analog N-carbamyl-Lglutamate (NCG), for recombinant or natural human CPS1

\begin{tabular}{lcccccc}
\hline \multirow{2}{*}{$\begin{array}{l}\text { Source } \\
\text { Activity }\end{array}$} & \multicolumn{5}{c}{ Apparent $\mathrm{K}_{\mathrm{m}}$ or $\mathrm{K}_{\mathrm{a}}$ value (mM) } \\
\cline { 3 - 7 } & $\mathrm{U} / \mathrm{mg}$ & $\mathrm{ATP}$ & $\mathrm{HCO}_{3}{ }^{-}$ & $\mathrm{NH}_{4}{ }^{+}$ & NAG & NCG \\
\hline Recombinant $^{\mathrm{a}}$ & 1.1 & 0.5 & 4.0 & 1.0 & 0.14 & 2.0 \\
Liver $^{\mathrm{b}}$ & 1.5 & 1.1 & 6.7 & 0.8 & 0.10 & - \\
Liver $^{\mathrm{c}}$ & 1.5 & 0.3 & 2.2 & 1.3 & 0.15 & 2.0 \\
\hline
\end{tabular}

${ }^{\mathrm{a}}$ Present work.

${ }^{\mathrm{b}}$ Pierson and Brien, 1980.

${ }^{\mathrm{c}}$ Rubio et al., 1981. 
Table 3. Influence of clinical CPS1D mutations on the kinetic parameters for the substrates and for NAG

\begin{tabular}{|c|c|c|c|c|c|c|c|c|}
\hline \multirow{3}{*}{$\begin{array}{l}\text { Enzyme } \\
\text { form }\end{array}$} & \multicolumn{8}{|c|}{ Substrate or activator } \\
\hline & \multicolumn{2}{|c|}{$\mathrm{NH}_{4}^{+}$} & \multicolumn{2}{|c|}{ Bicarbonate } & \multicolumn{2}{|c|}{ ATP } & \multicolumn{2}{|c|}{ NAG } \\
\hline & $\mathrm{V}^{[\mathrm{Am}]=\infty}$ & $\mathrm{K}_{\mathrm{m}}^{\mathrm{app}}$ & $\mathrm{V}^{[\mathrm{Bic}]=\infty}$ & $\mathrm{K}_{\mathrm{m}}^{\mathrm{app}}$ & $\mathrm{V}^{[\mathrm{ATP}]=\infty}$ & $\mathrm{K}_{\mathrm{m}}^{\text {app }}$ & $\mathrm{V}^{[\mathrm{NAG}]=\infty}$ & $\mathrm{K}_{\mathrm{a}}^{\mathrm{app}}$ \\
\hline & $\mathrm{U} / \mathrm{mg}$ & $\mathrm{mM}$ & $\mathrm{U} / \mathrm{mg}$ & $\mathrm{mM}$ & $\mathrm{U} / \mathrm{mg}$ & $\mathrm{mM}$ & $\mathrm{U} / \mathrm{mg}$ & $\mathrm{mM}$ \\
\hline
\end{tabular}

Recombinant wild type form and forms with polymorphisms

$\begin{array}{lllllllll}\text { Wild-type } & 1.19 & 1.0 & 1.23 & 4.0 & 1.22 & 0.47 & 1.15 & 0.14 \\ \text { p.Thr344Ala } & 1.06 & \begin{array}{l}1.2 \\ \pm 0.1\end{array} & 1.04 & 4.3 & 1.06 & 0.45 & 1.02 & 0.17 \\ \text { p.Gly1376Ser } & 1.16 & 1.1 & 1.28 & 4.5 & 1.22 & 0.45 & 1.17 & 0.12\end{array}$

Recombinant forms carrying clinical missense mutations

$\begin{array}{lllllllll}\text { p.Asn355Asp } & 0.25 & 1.0 & 0.26 & \begin{array}{l}4.6 \\ \pm 0.7\end{array} & 0.28 & 0.57 & 0.26 & 0.34 \\ \text { p.Tyr389Cys } & 0.73 & 1.1 & 0.79 & 4.2 & 0.73 & 0.43 & 0.70 & 0.12 \\ \text { p.Ala438Pro } & <0.01^{\mathrm{a}} & - & <0.01^{\mathrm{a}} & - & <0.01^{\mathrm{a}} & - & <0.01^{\mathrm{a}} & - \\ \text { p.Thr544Met } & 0.16 & 1.3 & 0.26 & 242 & 0.23 & 1.92 & 0.27 & 2.91 \\ & & & & & & & & \pm 0.38 \\ \text { p.Ala1378Thr } & 0.93 & 0.9 & 0.98 & 4.3 & 1.01 & 0.90 & 0.97 & 0.21 \\ \text { p.Thr1443Ala } & 0.04 & 1.0 & 0.034 & 3.6 & 0.04 & 0.62 & 0.14 & 23.4 \\ & & & & & \pm 0.01 & & & \pm 5.2\end{array}$

For clarity, standard errors are only given when they exceed $10 \%$ of the magnitude of the constant. The concentrations of $\mathrm{NH}_{4}{ }^{+}$, bicarbonate, ATP and NAG were varied in the following $\mathrm{mM}$ ranges: $0.1-20,0.3-625,0.05-10$ and $0-200$, respectively. When not varied, the concentrations of these ligands were 35, 50, 5 and $10 \mathrm{mM}$, respectively (except for bicarbonate in the case of the p.T544M mutation, which was $0.5 \mathrm{M}) . \mathrm{Mg}$ (as $\mathrm{MgSO}_{4}$ ) was always in $15 \mathrm{mM}$ excess over the ATP concentration.

${ }^{a}$ Detection limit 


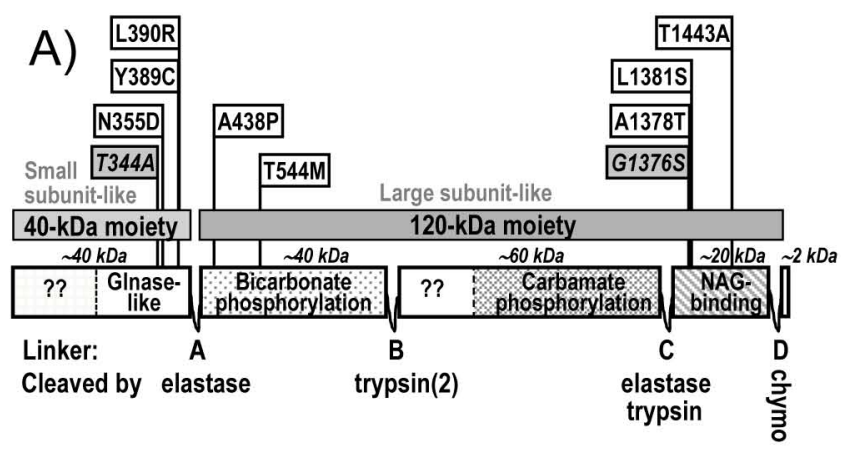

B) TRYPTIC DIGESTION

T1: $\sim 140 \mathrm{kDa}$ (anti-40 \& anti-120)
T2: $\sim 80 \mathrm{kDa}$ (anti-40 \& anti-120)
Human CPS1 $\frac{\text { Rat liver CPS1 }}{\text { Coomassie Coomassie Anti40 Anti120 }}$
T1: $\sim 140 \mathrm{kDa}$ (anti

T2: $\sim 80 \mathrm{kDa}$

T3: $\sim 60 \mathrm{kDa}$
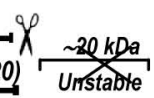

C

C)

\section{ELASTASE DIGESTION}

E1 (=T1): $\sim 40 \mathrm{kDa}$ (anti-40 \& anti-120)

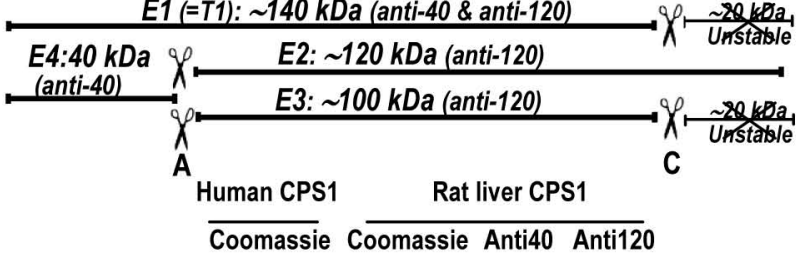

Undigested

E1: $\sim 140 \mathrm{kDa}$

E2: $\sim 120 \mathrm{kDa}$

E3: $-60 \mathrm{kDa}$

E4: $-40 \mathrm{kDa}$
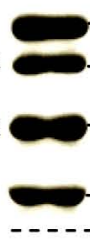


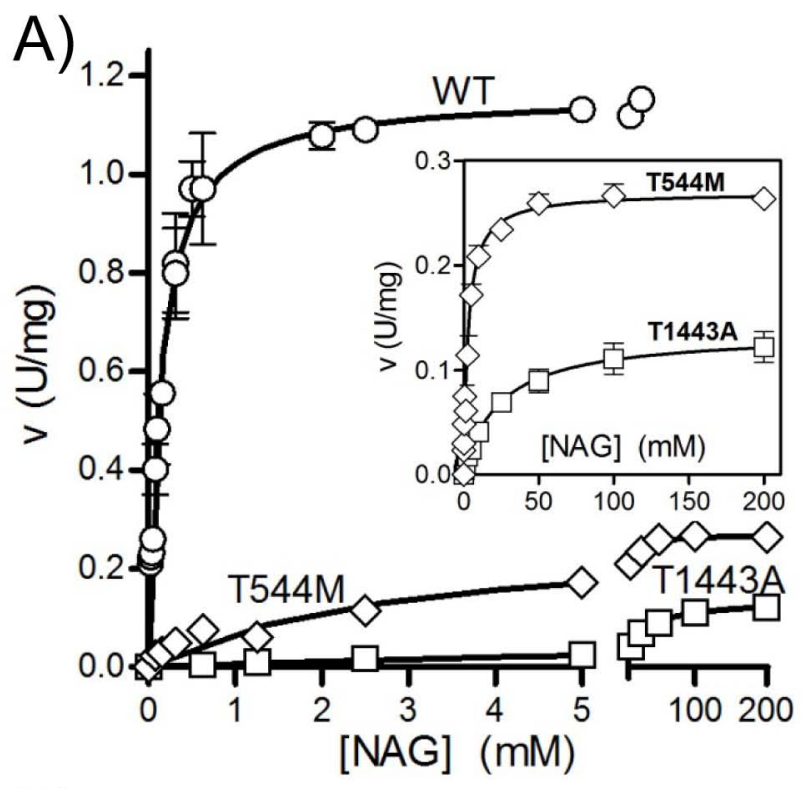

B)

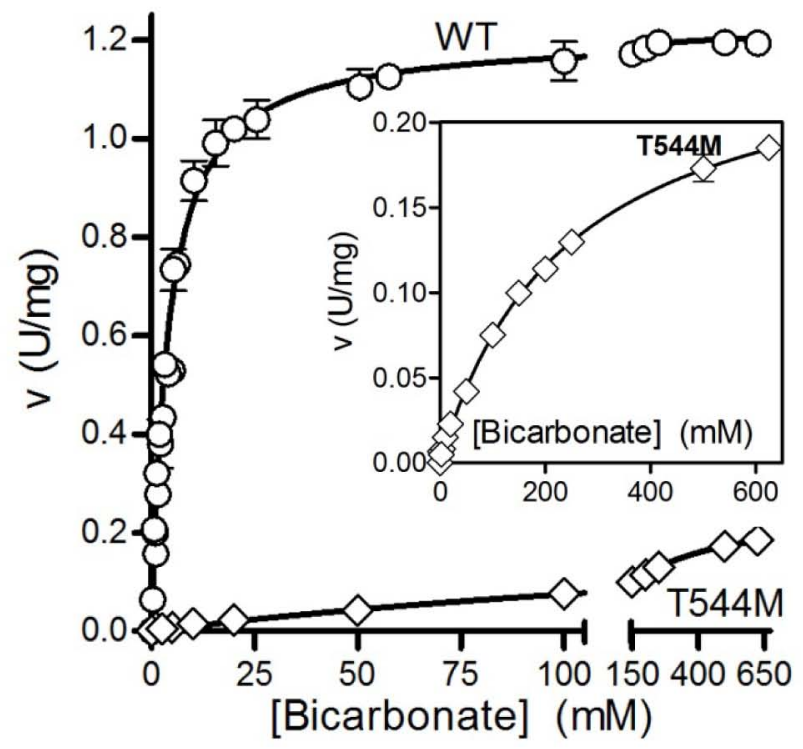


A)

human

liver
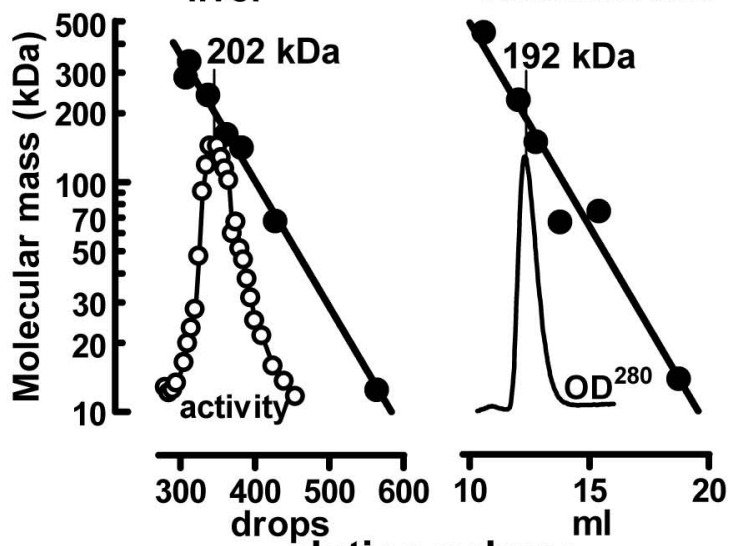

B) elution volume

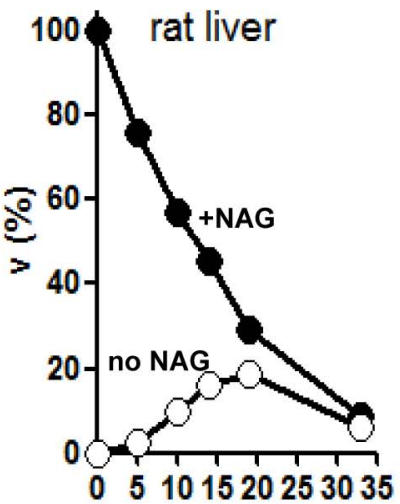


A)

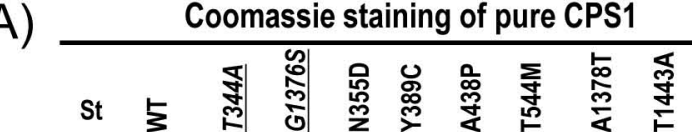
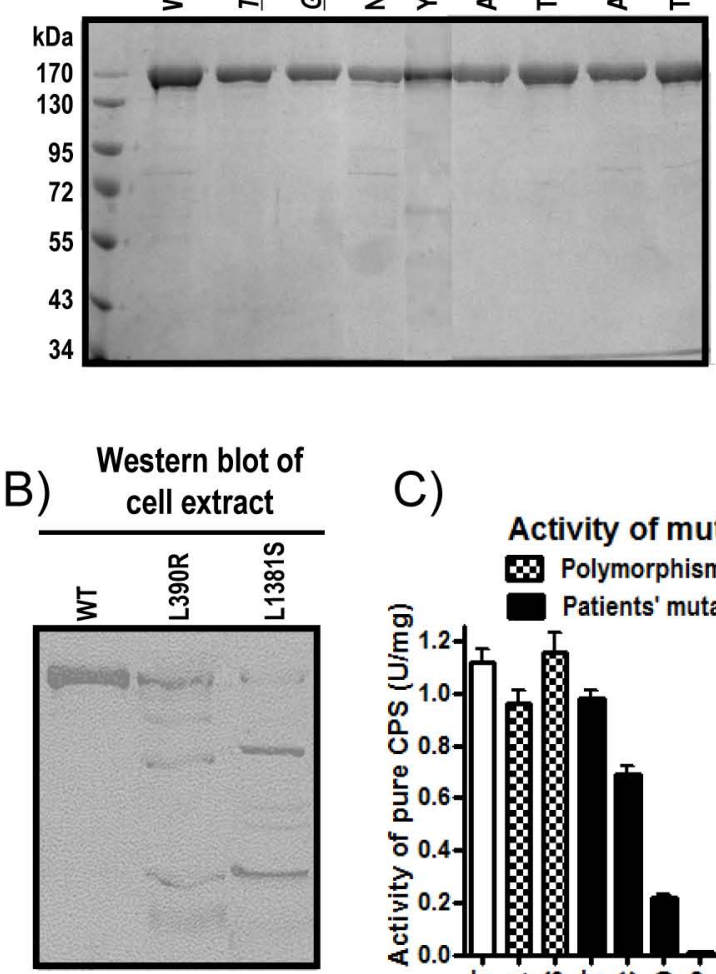

C)

Activity of mutants

$\boldsymbol{B}$ Polymorphisms

6) Patients' mutations

D)

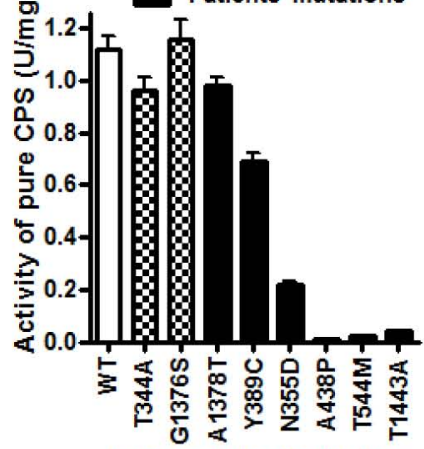

Amino acid substitution

Thermal stability

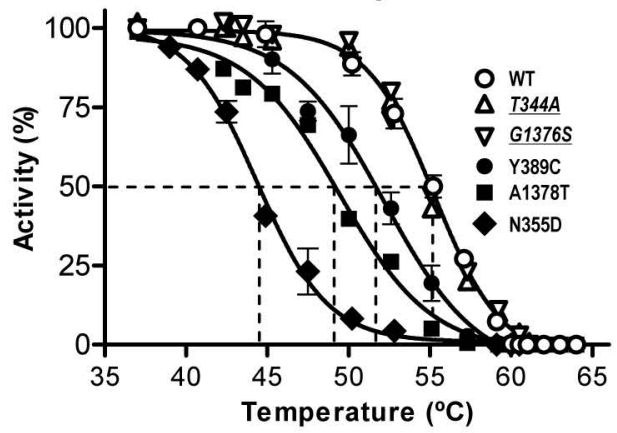




\section{Elastase treatment}

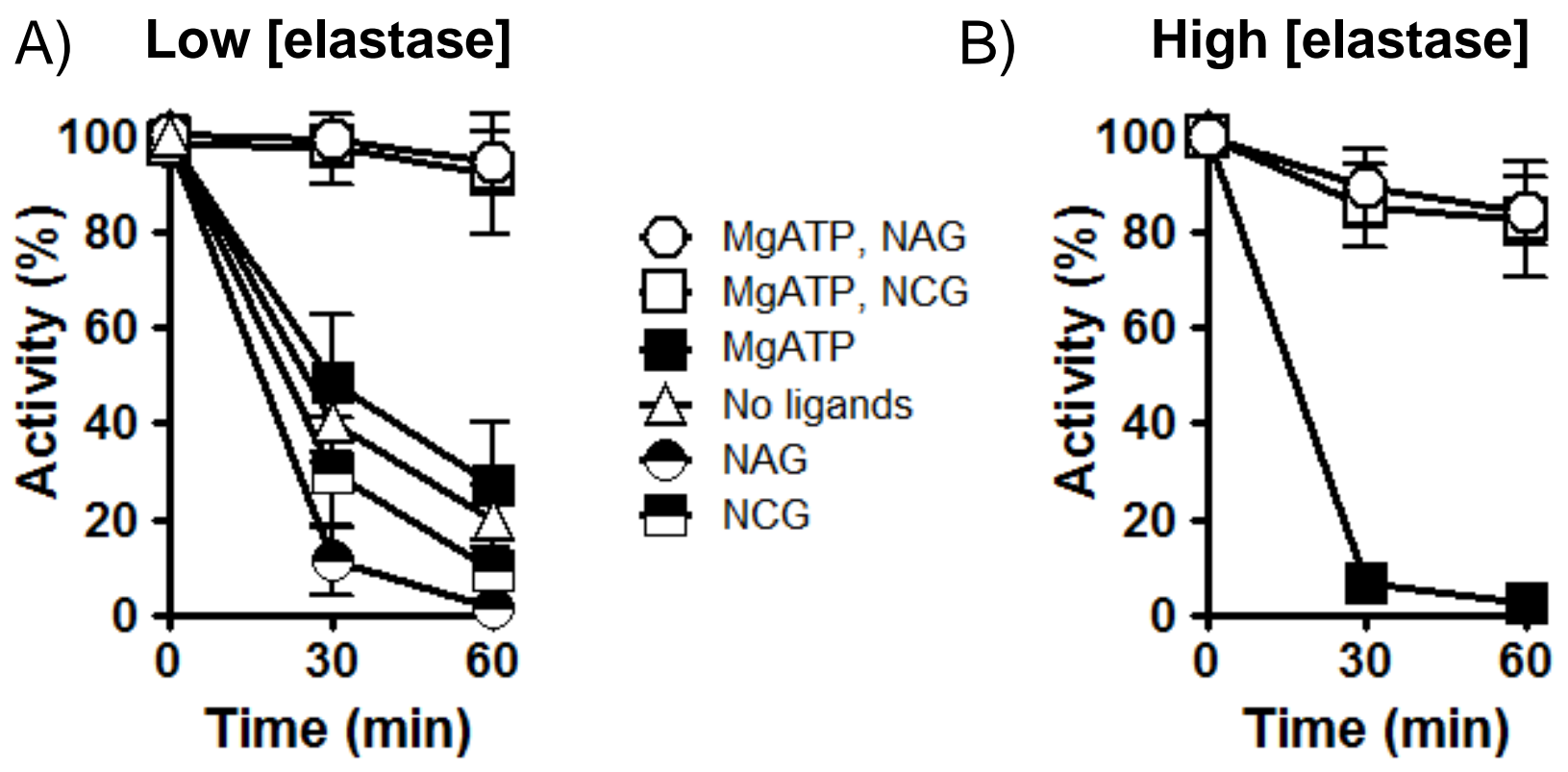

Thermal treatment

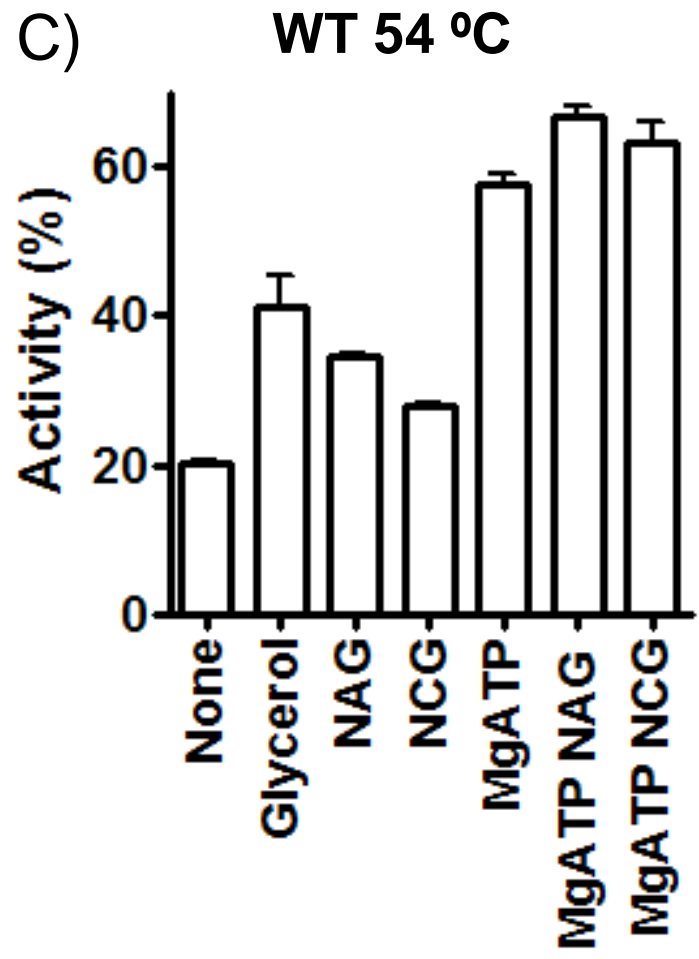

D) p.Ala1378Thr $52{ }^{\circ} \mathrm{C}$

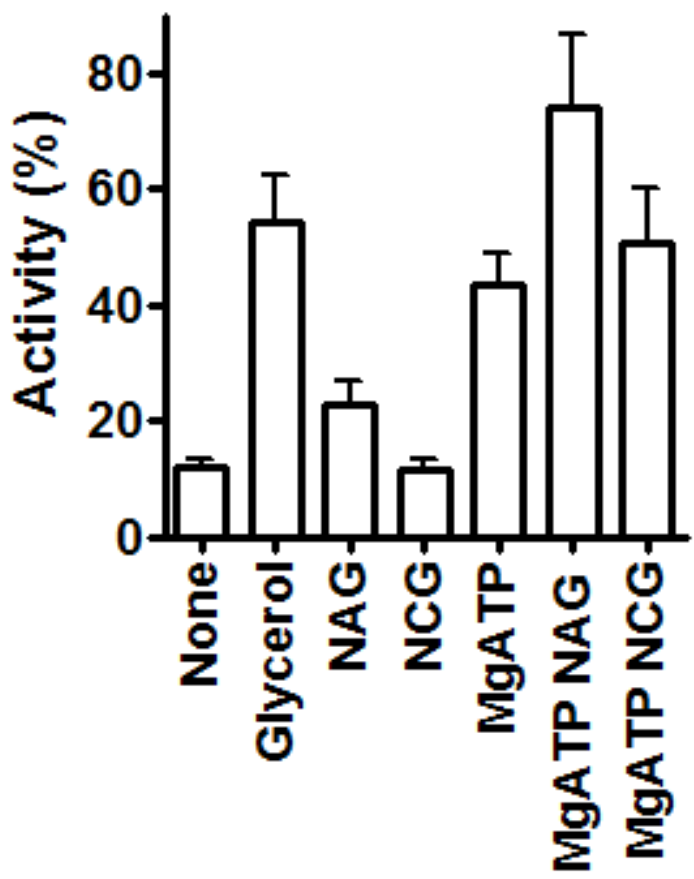


Supplementary Material for Diez-Fernández et al.

Molecular characterization of carbamoyl phosphate synthetase (CPS1) deficiency using human recombinant CPS1 as a key tool

Carmen Diez-Fernandez ${ }^{1,2}$, Ana I Martínez, ${ }^{2}$ Satu Pekkala, ${ }^{2}$ Belén Barcelona, ${ }^{1,2,3}$ Isabel Pérez-Arellano, ${ }^{2,3}$ Ana María Guadalajara, ${ }^{2}$ Marshall Summar, ${ }^{4}$ Javier Cervera, ${ }^{1,2,3^{*}}$ Vicente Rubio ${ }^{1,3^{*}}$

${ }^{1}$ Instituto de Biomedicina de Valencia (IBV-CSIC), Spain; ${ }^{2}$ Centro de Investigación Príncipe Felipe, Valencia, Spain; ${ }^{3}$ Group 739, CIBERER, ISCIII, Spain; ${ }^{4}$ Childrens National Medical Center, Washington DC, USA 
Supplementary Material for Diez-Fernández et al.

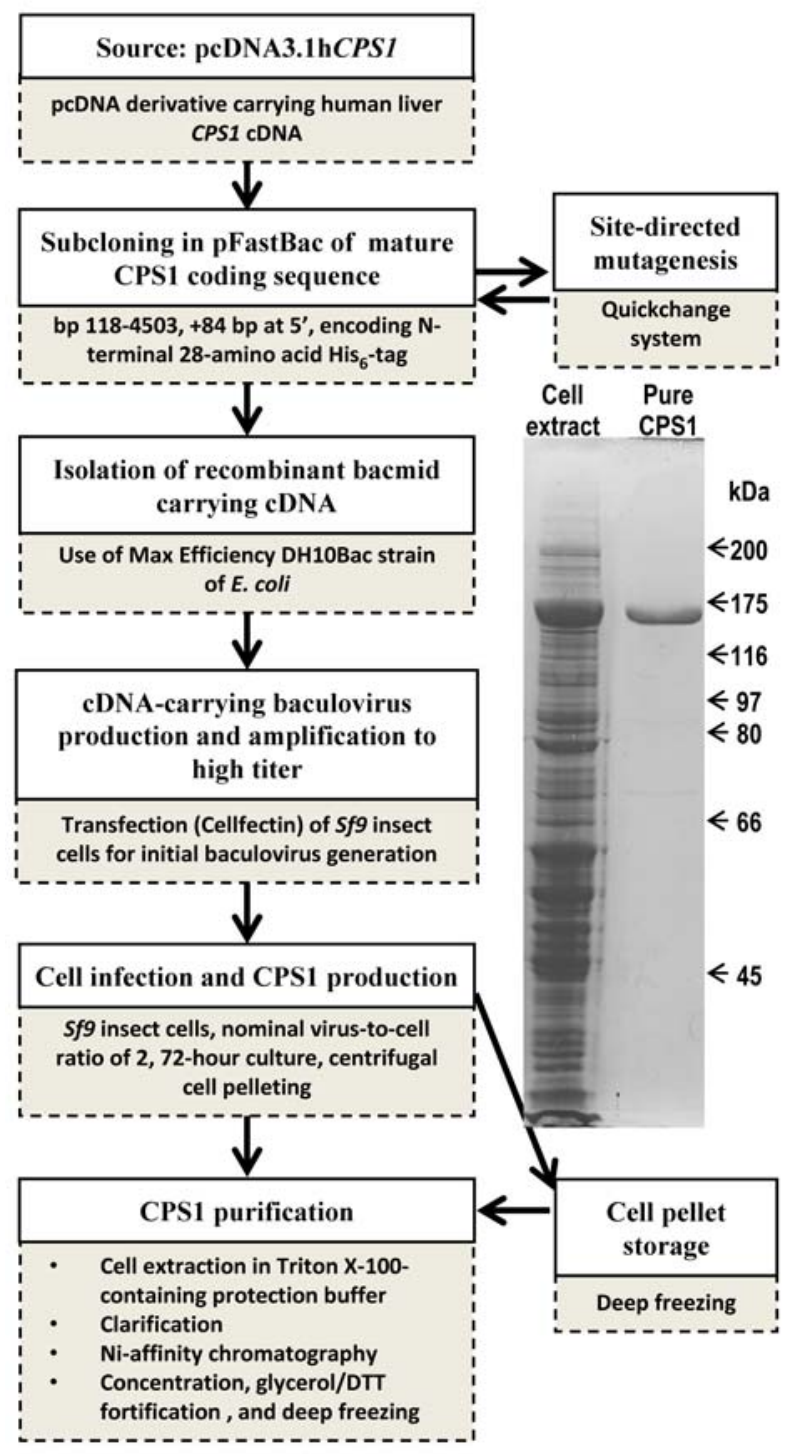

Supp. Figure S1. Diagram schematizing the steps of the production of recombinant human CPS1. The gel (SDS-PAGE, Coomassie staining, the arrows give the positions of protein standards of the indicated polypeptide masses) illustrates the presence of abundant soluble CPS1 protein in the postcentrifugal supernatant of the cell extract (left track) and the essential homogeneity of the purified protein (right track). 


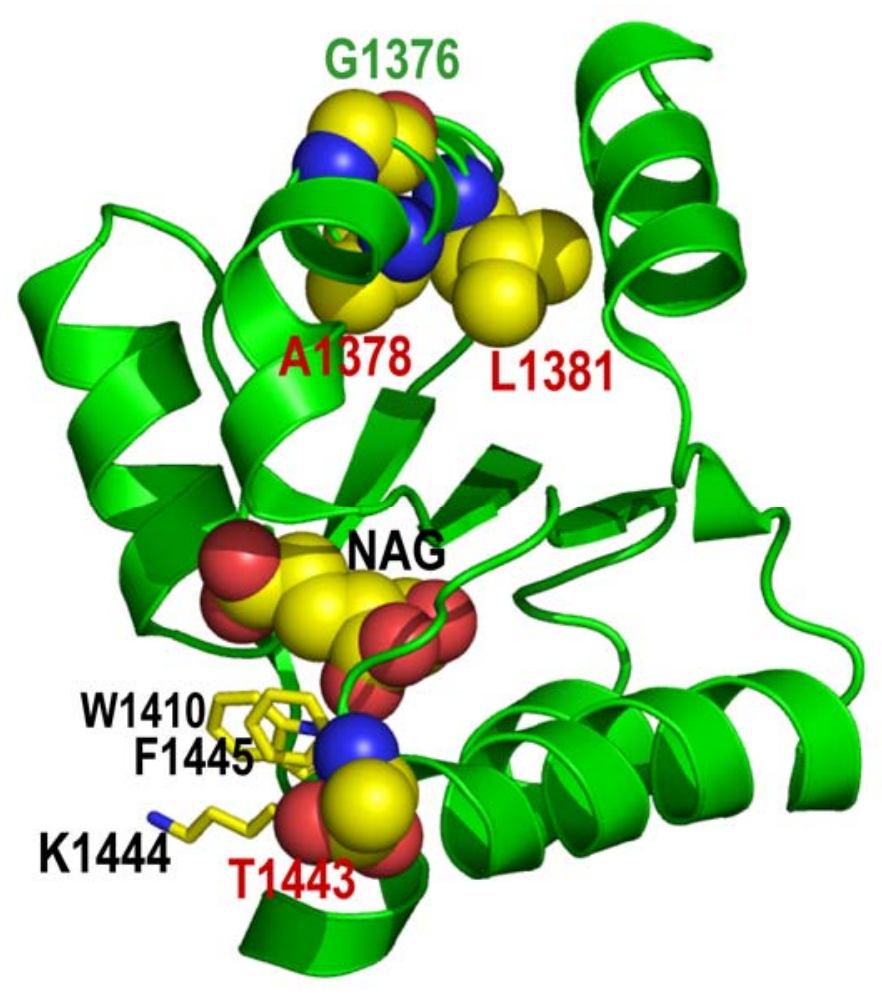

Supp. Figure S2. Location in the structure of the C-terminal domain of the amino acids whose substitutions are studied here. The protein is in ribbon representation. Bound NAG [Pekkala et al., 2009] and the amino acids that are replaced are represented in spheres and are labeled whereas the NAG site lid residues W1410, F1445 and K1444 are shown in sticks representation. Green and red labeling correspond, respectively, to the polymorphism and to clinical mutations. NAG, and the amino acids forming the NAG site lid, are labeled in black. In NAG and in the highlighted residues, $\mathrm{C}, \mathrm{N}$ and $\mathrm{O}$ atoms are colored yellow, blue and red, respectively. This figure was prepared with PyMOL (http://www.pymol.org). 
Supplementary Material for Diez-Fernández et al.

Supp. Table S1. Synthetic oligonucleotides used in cloning and site-directed mutagenesis

\begin{tabular}{|c|c|c|}
\hline Name/mutation & Direction & Sequence $5{ }^{\prime}-3^{\prime}$ \\
\hline Cloning_F & Forward & CGCATGGATCCGTCTGTCAAGGCACAGACA $^{a}$ \\
\hline Cloning_R & Reverse & TTTATTTGGATCCACAAAATCCACAGG ${ }^{a}$ \\
\hline p.T344A & Forward & CTATGCCTTGGACAACGCTCTCCCTGCTGGC \\
\hline p.T344A & Reverse & GCCAGCAGGGAGAGCGTTGTCCAAGGCATAG $^{\text {b }}$ \\
\hline p.N355D & Forward & CACTTTTTGTGGATGTCAACGATC ${ }^{b}$ \\
\hline p.N355D & Reverse & GATCGTTGACATCCACAAAAAGTG ${ }^{b}$ \\
\hline p.Y389C & Forward & CAATAGACACTGAGTGCCTGTTTGATTCC ${ }^{b}$ \\
\hline p.Y389C & Reverse & GAATCAAACAGGCACTCAGTGTCTATTGG ${ }^{b}$ \\
\hline p.L390R & Forward & CAATAGACACTGAGTACCGGTTTGATTCC ${ }^{b}$ \\
\hline p.L390R & Reverse & GAATCAAACCGGTACTCAGTGTCTATTGG ${ }^{b}$ \\
\hline p.A438P & Forward & CCATTGGTCAGCCTGGAGAATTTG ${ }^{\text {b }}$ \\
\hline p.A438P & Reverse & GTAATCAAATTCTCCAGGCTGACCAATGGAC \\
\hline p.T544M & Forward & CATTATGGCTATGGAAGACAGGCAGCTG ${ }^{b}$ \\
\hline p.T544M & Reverse & CTGCCTGTCTTCCATAGCCATAATGGAC ${ }^{\text {b }}$ \\
\hline p.G1376S & Forward & CCAAGATTCCTTAGTGTGGCTGAACAATTAC ${ }^{b}$ \\
\hline p.G1376S & Reverse & GTAATTGTTCAGCCACACTAAGGAATCTTGGCC ${ }^{b}$ \\
\hline p.A1378T & Forward & CCTTGGTGTGACTGAACAATTAC ${ }^{b}$ \\
\hline p.A1378T & Reverse & GTAATTGTTCAGTCACACCAAGGAATC ${ }^{b}$ \\
\hline p.L1381S & Forward & CTTGGTGTGGCTGAACAATCACACAATGAAGGTTTCAAG ${ }^{\mathrm{b}}$ \\
\hline p.L1381S & Reverse & GAAACCTTCATTGTGTGATTGTTCAGCCACACCAAGG ${ }^{\text {b }}$ \\
\hline p.T1443A & Forward & СТTСССААСАACAАCGCTAAATTTGTC ${ }^{b}$ \\
\hline p.T1443A & Reverse & GGACAAATTTAGCGTTGTTGTTGGGAAG ${ }^{\text {b }}$ \\
\hline
\end{tabular}

${ }^{\mathrm{a}}$ Underlining marks the BamH1 restriction sites

${ }^{\mathrm{b}}$ Bold type indicate base substitutions to introduce the desired mutation. 